Prepared for the U.S. Department of Energy

under Contract DE-AC05-76RL01830

\title{
Online Analysis of Wind and Solar Part II: Transmission Tool
}

\author{
YV Makarov \\ $\mathrm{J} \mathrm{Ma}$ \\ PV Etingov \\ K Subbarao
}

January 2012

Pacific Northwest

NATIONAL LABORATORY

Proudly Operated by Battelle Since 1965 



\title{
DISCLAIMER
}

United States Government. Neither the United States Government nor any agency thereof, nor Battelle Memorial Institute, nor any of their employees, makes any warranty, express or implied, or assumes any legal liability or responsibility for the accuracy, completeness, or usefulness of any information, apparatus, product, or process disclosed, or represents that its use would not infringe privately owned rights. Reference herein to any specific commercial product, process, or service by trade name, trademark, manufacturer, or otherwise does not necessarily constitute or imply its endorsement, recommendation, or favoring by the United States Government or any agency thereof, or Battelle Memorial Institute. The views and opinions of authors expressed herein do not necessarily state or reflect those of the United States Government or any agency thereof.

\author{
PACIFIC NORTHWEST NATIONAL LABORATORY \\ operated by \\ BATTELLE \\ for the \\ UNITED STATES DEPARTMENT OF ENERGY \\ under Contract DE-AC05-76RL01830 \\ Printed in the United States of America \\ Available to DOE and DOE contractors from the \\ Office of Scientific and Technical Information, \\ P.O. Box 62, Oak Ridge, TN 37831-0062; \\ ph: (865) 576-8401, fax: (865) 576-5728 \\ email: reports@adonis.osti.gov \\ Available to the public from the National Technical Information Service, \\ U.S. Department of Commerce, 5285 Port Royal Rd., Springfield, VA 22161 \\ ph: (800) 553-6847, fax: (703) 605-6900 \\ email: orders@ntis.fedworld.gov \\ online ordering: http://www.ntis.gov/ordering.htm
}

This document was printed on recycled paper.

$(8 / 00)$ 


\section{ACKNOWLEDGEMENTS}

This work was funded by the Public Interest Energy Research (PIER) program in renewable energy at the California Energy Commission and managed by the California Institute for Energy and Environment. This report was prepared with substantial support from California Independent System Operator personnel.

The authors would like to thank Gil Bindewald and Stan Calvert, U.S. Department of Energy; Mike Gravely, Pedro Gomez, and Jamie Patterson, California Energy Commission; Merwin Brown, Larry Miller, and Jim Cole, California Institute for Energy and Environment; and Mark Rothleder, William Bonnell, Hani Alarian, Jim McIntosh, Sirajul Chowdhury, Zhijun (June) Xie, and Ajay Mannepalli, California Independent System Operator, for providing the project team with consultations, day-by-day support, and discussions essential to this work.

The authors would also like to thank Managers Carl H. Imhoff, Dale King, Evan O. Jones, Mark P. Morgan, Ron Melton, and Landis Kannberg, Staff Tony Nguyen, John C. Bower (retired), Contracting Officer Sheena Kanyid, Project Specialist Susan Arey, and Administrative Assistant Nikki Stringer, Pacific Northwest National Laboratory, for supporting this work.

Many thanks go to Document Production Specialist Kathy Neiderhiser, Pacific Northwest National Laboratory, for formatting the final manuscript.

\section{DISCLAIMER}

This report was prepared as the result of work sponsored by the California Energy Commission. It does not necessarily represent the views of the Energy Commission, its employees or the State of California. The Energy Commission, the State of California, its employees, contractors and subcontractors make no warrant, express or implied, and assume no legal liability for the information in this report; nor does any party represent that the uses of this information will not infringe upon privately owned rights. This report has not been approved or disapproved by the California Energy Commission nor has the California Energy Commission passed upon the accuracy or adequacy of the information in this report. 
PNNL-21105

\title{
Online Analysis of Wind and Solar Part II: Transmission Tool
}

\author{
YV Makarov \\ PV Etingov \\ $\mathrm{J}$ Ma \\ K Subbarao
}

January 2012

Prepared for

California Institute for Energy and Environment and the California Energy Commission

via U.S. Department of Energy

Contract DE-AC05-76RL01830

Related Services

Pacific Northwest National Laboratory

Richland, Washington 99352 



\section{PREFACE}

The California Energy Commission Public Interest Energy Research (PIER) Program supports public interest energy research and development that will help improve the quality of life in California by bringing environmentally safe, affordable, and reliable energy services and products to the marketplace.

The PIER Program conducts public interest research, development, and demonstration (RD\&D) projects to benefit California. The PIER Program strives to conduct the most promising public interest energy research by partnering with RD\&D entities, including individuals, businesses, utilities, and public or private research institutions.

PIER funding efforts are focused on the following RD\&D program areas:

- Buildings End-Use Energy Efficiency

- Energy Innovations Small Grants

- Energy-Related Environmental Research

- Energy Systems Integration

- Environmentally Preferred Advanced Generation

- Industrial/Agricultural/Water End-Use Energy Efficiency

- Renewable Energy Technologies

- Transportation

This report is the final report for the "Online Analysis of Wind and Solar" project (contract number: 500-07-537, work authorization number: POTPO1-X11) conducted by the Pacific Northwest National Laboratory. The information from this project contributes to PIER's Energy Systems Integration program area.

For more information about the PIER Program, please visit the Energy Commission's website at http://www.energy.ca.gov/research/, or contact the Energy Commission at 916-654-4878. 



\section{ABSTRACT}

Interacting wind, solar, and load forecast errors can create significant unpredictable impacts on the transmission system, congestion, voltage and reactive power stability margins. These impacts will be increasing with the increasing penetration levels of variable renewable generation in the Western Interconnection and California power systems. To maintain a secure system reliability level, the probability and the magnitude of the impacts should be evaluated and communicated to the system operators. Based on this information, the system power flow limits, dispatches, voltage levels, and available reactive power margins could be adjusted to minimize the risk of system problems and failures to an acceptable level whenever it is required.

To facilitate wider penetration of renewable resources without compromising system reliability, two tools intended for use by California Independent System Operator (CAISO) power grid operators have been developed for predicting and displaying the operational impacts of uncertainties in forecasts of loads and renewable generation. The first tool (so-called "ramping tool") addresses real-time (load following) capacity and ramping requirements, and the second ("transmission tool") addresses voltage, stability and transmission congestion caused by renewables resources (mainly wind power and solar power generation). The first tool is an industry-grade product connected to the California ISO systems and operated in real time in the California ISO Control Center. This tool is described in a separate report prepared and submitted by Pacific Northwest National Laboratory (PNNL).

Based on a contract with the California Energy Commission (CEC) and California Institute for Energy and Environment (CIEE), PNNL is developing a second tool for predicting transmission uncertainties and related impacts ("transmission tool" - TT). The present report addresses this second tool -“transmission tool". 



\section{TABLE OF CONTENTS}

PREFACE

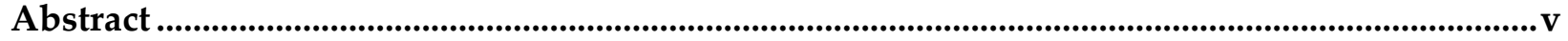

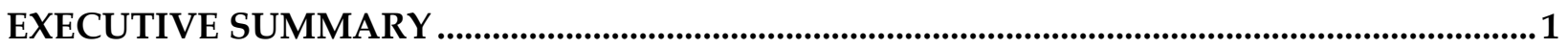

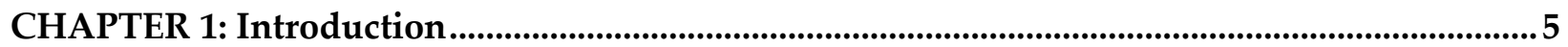

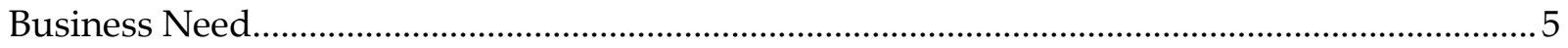

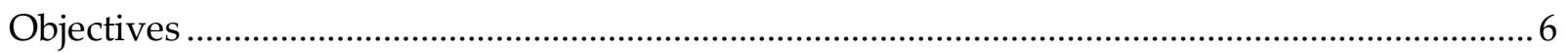

CHAPTER 2: Real-Time Voltage Stability Analysis Software Description and Connectivity

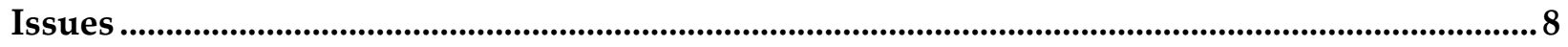

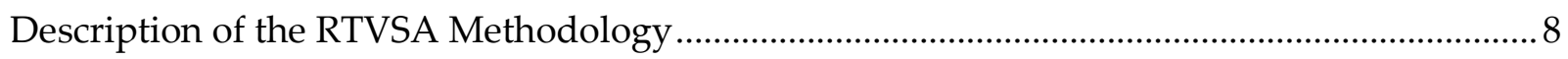

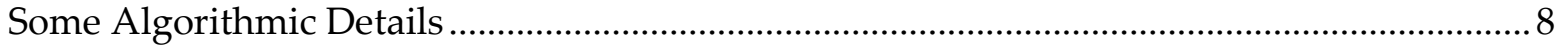

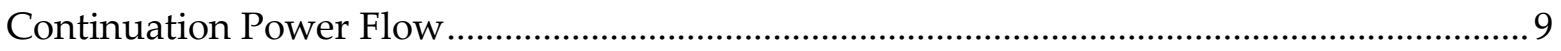

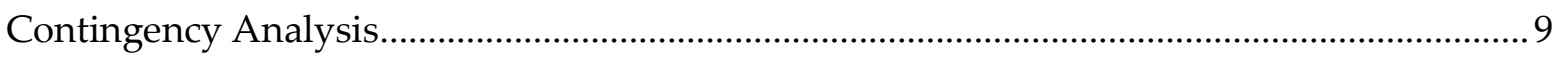

CAISO RTVSA Architecture and Information Flow (Varghese et al. 2008) ............................... 9

Network Model and Supplemental Data (Varghese et al. 2008) ............................................ 9

Dynamic Input Data and Interface (Varghese et al. 2008) ...................................................... 9

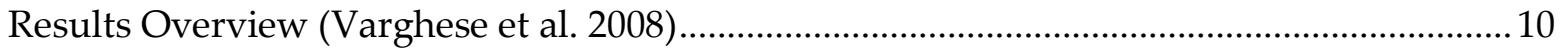

Output Data Interface (Varghese et al. 2008) ........................................................................... 10

Definitions and Output Parameters ..................................................................................... 11

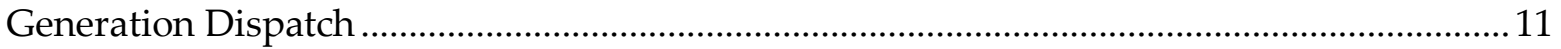

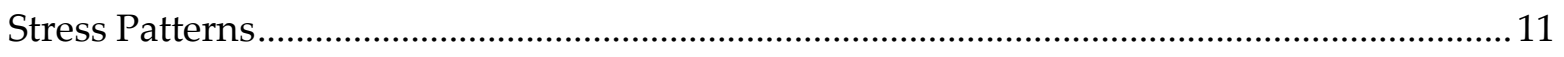

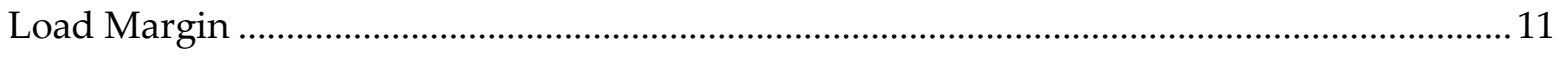

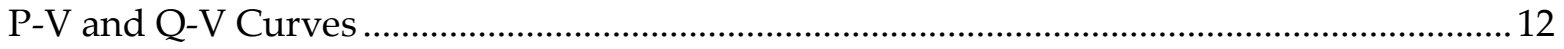

Critical Interface and Deterministic Transmission Limits ................................................... 14

Selected TT-RTVSA Integration Approach and its Implications ............................................. 14

CHAPTER 3: Transmission Tool Outputs and Their Utilization ...................................................17

Probability Distribution of Transmission Flows...................................................................... 17

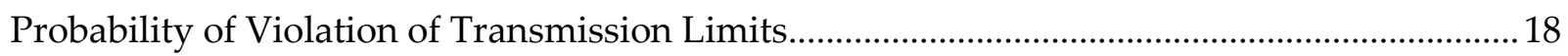


Probability Distribution of Voltage Levels and Reactive Power Margins

CHAPTER 4: Connectivity with Visualization Software .....................................................................2 23

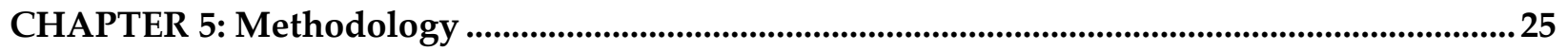

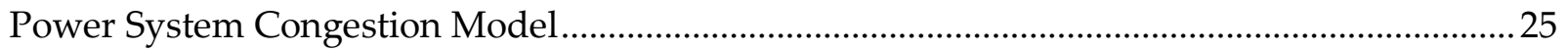

Linearized Incremental Power Flow Model and PTDF .......................................................... 27

Mathematical Definition of the Incremental Model.............................................................. 28

Incremental Model Development Using Power World Simulator ........................................ 30

CHAPTER 6: High Level Transmission Tool Description ................................................................... 32

Connectivity Diagram with Real-Time Voltage Stability Analysis Tool and CAISO

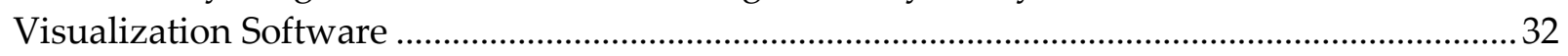

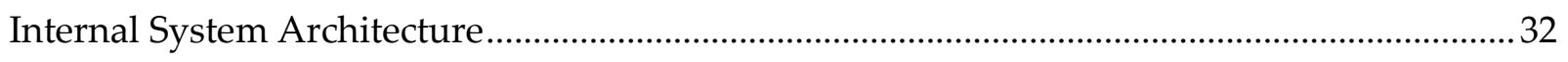

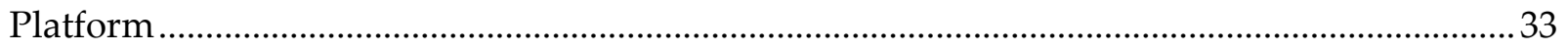

System Features and Benefits for CAISO ….......................................................................... 33

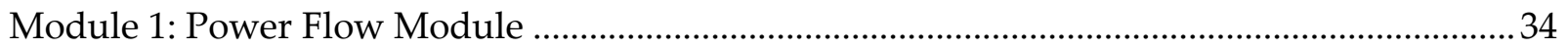

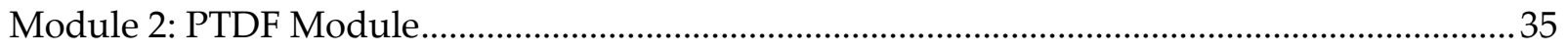

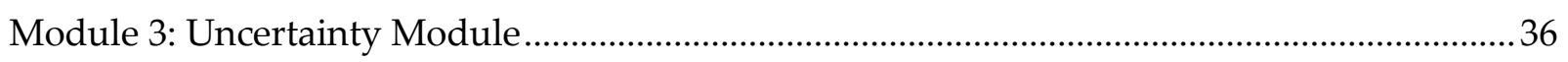

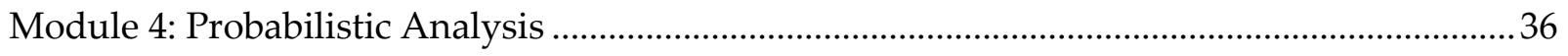

CHAPTER 7: User Interface Prototype........................................................................................................3 37

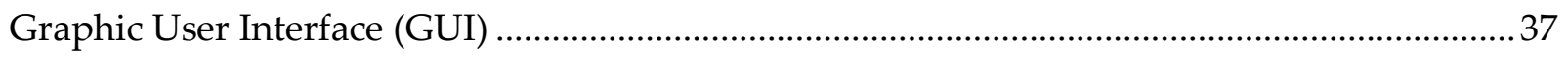

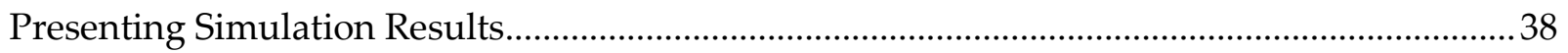

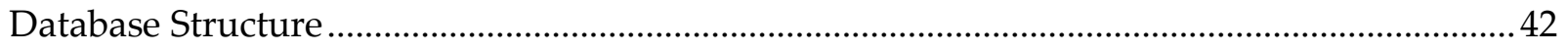

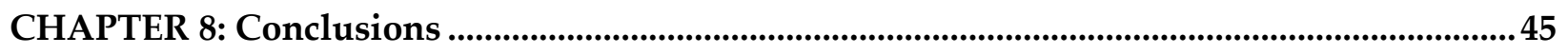

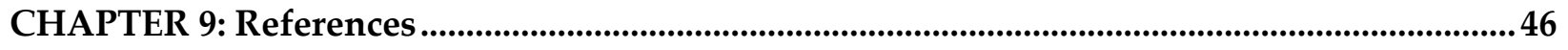

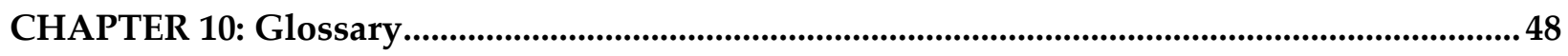




\section{LIST OF FIGURES}

Figure 1: Probabilistic Analysis of Transmission Interface Power Flow ........................................ 3

Figure 2: Conceptual Design of the Visualization Display Based on Google Earth Technology ... 4

Figure 3: The Current Transmission Paths Used by RTVSA Tool and Their Status Monitors

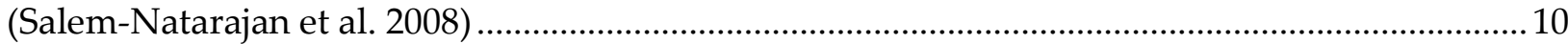

Figure 4: RTVSA Architecture (Varghese et al. 2008) .................................................................. 11

Figure 5: P-V Curves and Derived System Characteristics (Varghese et al. 2008) ....................... 12

Figure 6: P-V and Q-V Curves Produced by VSA\&E Tool (Li et al. 2004) .................................... 13

Figure 7: Critical Interface and Deterministic Transmission Limits ............................................. 14

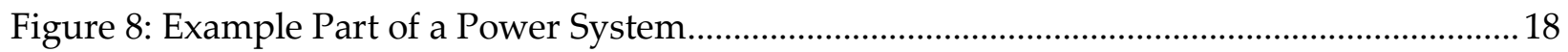

Figure 9: Probabilistic Limits for Base Case Conditions and Contingencies ................................. 19

Figure 10: Advisory Information for Probabilistic Assessment of Congested Transmission Paths

Figure 11: Mean and the Maximum Overloads ............................................................................. 21

Figure 12: The Idea of Using P-V and Q-V Curves to Obtain Probability Distributions of Voltages and Reactive Power....

Figure 13: A Conceptual Screen for Visual Presentation of Transmission Tool Results on a Conventional Map

Figure 14: A Google Earth Design of the TT Screen......................................................................24

Figure 15: Active Congestion Zones and Branch Groups (Department of Market Monitoring 2007) 25

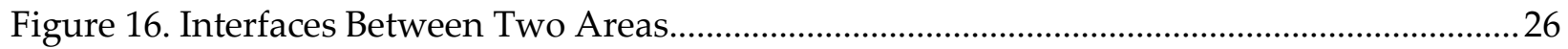

Figure 17. Multi-Line Interfaces Between Areas.............................................................................2 26

Figure 18: Zonal Structure of the WECC System........................................................................28

Figure 19. WECC System Transmission Lines And Paths (WECC 2005).....................................29

Figure 20: Connections and Type of Information to be Exchanged PNNL's TT and RTVSA and

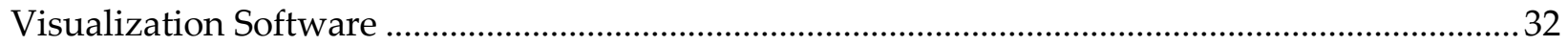

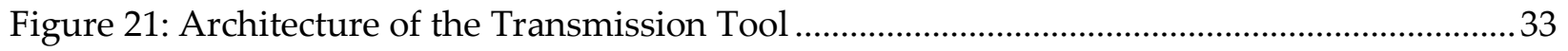

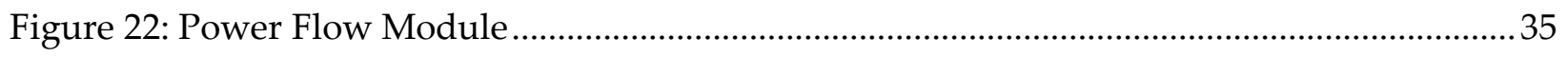

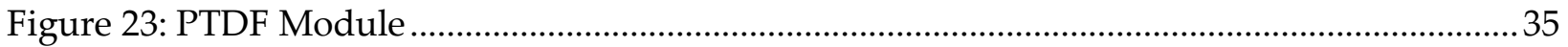




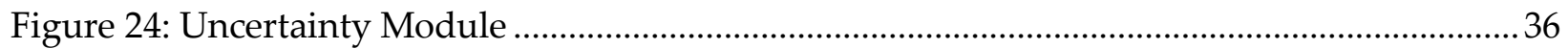

Figure 25: Main GUI of the Transmission Tool............................................................................. 37

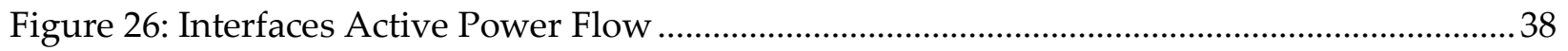

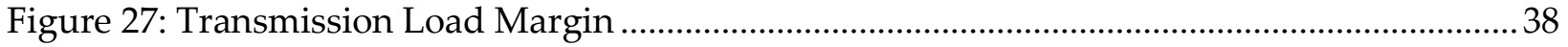

Figure 28: Simulation Results - Incremental Power Flow............................................................ 39

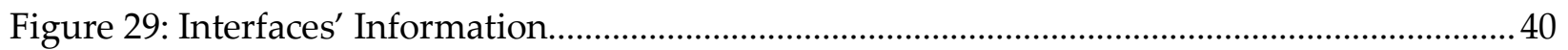

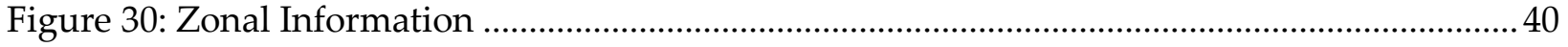

Figure 31: Probability of Power Flow for Base Case ..................................................................... 41

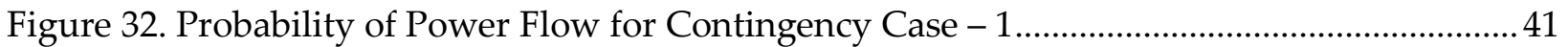

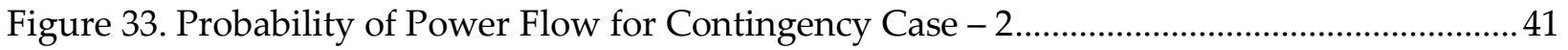

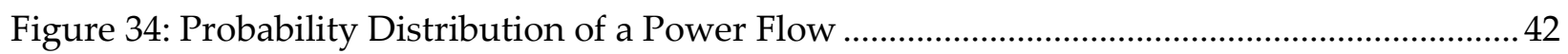

\section{LIST OF TABLES}

Table 1: P-V Curves and Derived System Characteristics (Varghese et al. 2008) ........................ 13

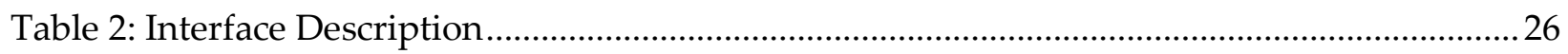

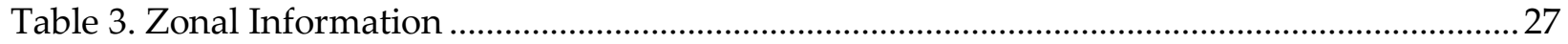

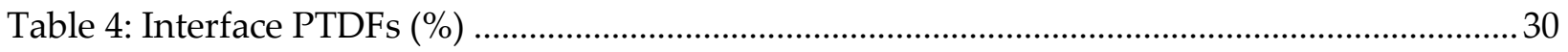

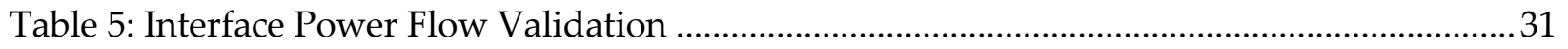

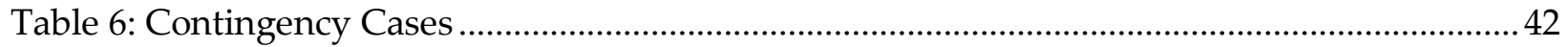

Table 7: Transmission Limits and Margin for Base Case................................................................ 42

Table 8: Transmission Limits and Margin for a Contingency Case ................................................ 43

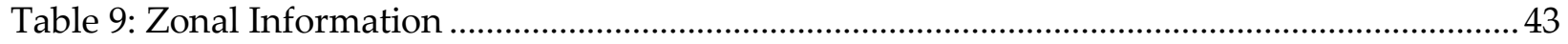

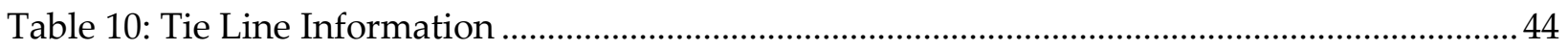




\section{EXECUTIVE SUMMARY}

Interacting wind, solar, and load forecast errors can create significant unpredictable impacts on the transmission system, congestion, voltage and reactive power stability margins. These impacts will be increasing with the increasing penetration levels of variable renewable generation in the Western Interconnection and California power systems. To maintain a secure system reliability level, the probability and the magnitude of the impacts should be evaluated and communicated to the system operators. Based on this information, the system power flow limits, dispatches, voltage levels, and available reactive power margins could be adjusted to minimize the risk of system problems and failures to an acceptable level whenever it is required.

To facilitate wider penetration of renewable resources without compromising system reliability, two tools intended for use by California Independent System Operator (CAISO) power grid operators have been developed for predicting and displaying the operational impacts of uncertainties in forecasts of loads and renewable generation. The first tool (so-called "ramping tool") addresses real-time (load following) capacity and ramping requirements, and the second ("transmission tool") addresses voltage, stability and transmission congestion caused by renewables resources (mainly wind power and solar power generation). The first tool is an industry-grade product connected to the California ISO systems and operated in real time in the California ISO Control Center. This tool is described in a separate report prepared and submitted by Pacific Northwest National Laboratory (PNNL).

Based on a contract with the California Energy Commission (CEC) and California Institute for Energy and Environment (CIEE), PNNL is developing a second tool for predicting transmission uncertainties and related impacts ("transmission tool" - TT). The present report addresses this second tool -“transmission tool".

The TT analyzes impacts on:

1. Congestion;

2. Voltage and transient stability margins, and

3. Voltage reductions and reactive power margins.

The TT analyzes the impact on the base case and under user-specified contingencies, so that the most limiting contingency is determined and addressed.

Information provided to the real-time dispatchers by the transmission tool includes:

1. The probability of violation of transmission constraints: this probability can be compared against the corresponding threshold risk levels specified by the users. If the violation probability exceeds the threshold, the TT issues advisory information suggesting an increase of the security margin helping to lower the probability of violation to an acceptable level.

2. The average and the maximum size of violations: the average size of violations is compared against their user-specified thresholds. If the average expected violation exceeds a 
user-specified threshold, the TT issues advisory information suggesting an increase of the security margin helping to lower the average size of violation to an acceptable level.

3. The available probability-based security margin (a distance to violation) and recommendations on its increase whenever is required, and

4. Visualization of the transmission impacts, real time dispatcher alerts and advisory information on a Western Electricity Coordinating Council (WECC) or California system map.

The proposed transmission tool has several very important advantages and opportunities for the California system operators:

1. Better quantification of available security margins. Because the analyzed transmission impacts are caused by random variations of forecast errors in different parts of the system, they are not predictable in a deterministic sense. Based on a statistical analysis of multiple forecast errors, the tool provides a unique opportunity to adjust security margins depending on the risk (expected size and probability) of potential transmission violations.

2. Better reliability level. By adjusting the system security margins on critical paths in the system, the tool helps to prevent potential violations caused by random variations of system load and variable generation around their forecasted values.

3. Better utilization of transmission assets. In cases when the deterministic security margin is excessive, the tool will provide recommendations to reduce this margin based on the actual variability of the flows in the analyzed critical paths.

4. Better situation awareness and predictive system monitoring. The TT algorithm is run for multiple look-ahead dispatch intervals and possible contingencies. Based on this information, system dispatchers will be informed about potential violations and associated risks on all critical paths in the system, and on the most critical contingencies as well as the expected time to violations.

5. Preventive control. As a result of its look-ahead feature, the TT algorithm leaves some time for mitigation measures, helping to reduce the expected size and probability of violations to an acceptable level.

The transmission tool is a standalone working prototype product ${ }^{1}$ that demonstrates the key features and advantages of the methodology developed by PNNL. The initial design incorporates all required essential informational, analytical, and visualization functions. Further development and integration with vendor-supported software at California ISO are necessary for deployment.

\footnotetext{
${ }^{1}$ Based on previous input by California ISO in meetings organized by CEC, the ramping tool was given higher priority and therefore a higher share of the project resources. This necessitated a reduction in the resources for the transmission tool, and the scope is therefore limited to developing a prototype of the tool that demonstrates the main capabilities.
} 
Since the beginning of the project, the California ISO has implemented a real-time voltage stability analysis (RTVSA) tool (voltage stability analysis and enhancement (VSA\&E) tool developed by Bigwood Systems Company), and advanced visualization and data processing tools (developed by Space Time Insight Company). In this situation, the project priorities and scope has changed by California ISO. Developing of a stand-alone fully- functional transmission tool would be redundant. Based on recommendation of the California ISO project support team, a decision was made to develop a TT prototype and its integration approach with the tools already installed and used by California ISO. The connectivity issues are addressed in this report from the methodology and system model perspective to provide future connectivity of the future industry-grade applications with the California ISO systems generally, and with the Bigwood real-time stability analysis applications, as well as with the Space Time Insight visualization tools.

Developed methodology is based on the Monte-Carlo simulations and statistical analysis of different sources of uncertainty that can impact on the transmission network. The developed methodology also includes linearized power flow model to calculate incremental active power flows in the transmission network caused by forecasting errors.

Figure 1 shows a screenshot of the probabilistic analysis display. The user can select any monitored transmission interface to check the probability of power flow distribution via interface at specific look-ahead operating intervals. The user is also advised if the interface transmission limit potentially can be violated, and what the probability and size of this violation might be.

Figure 1: Probabilistic Analysis of Transmission Interface Power Flow

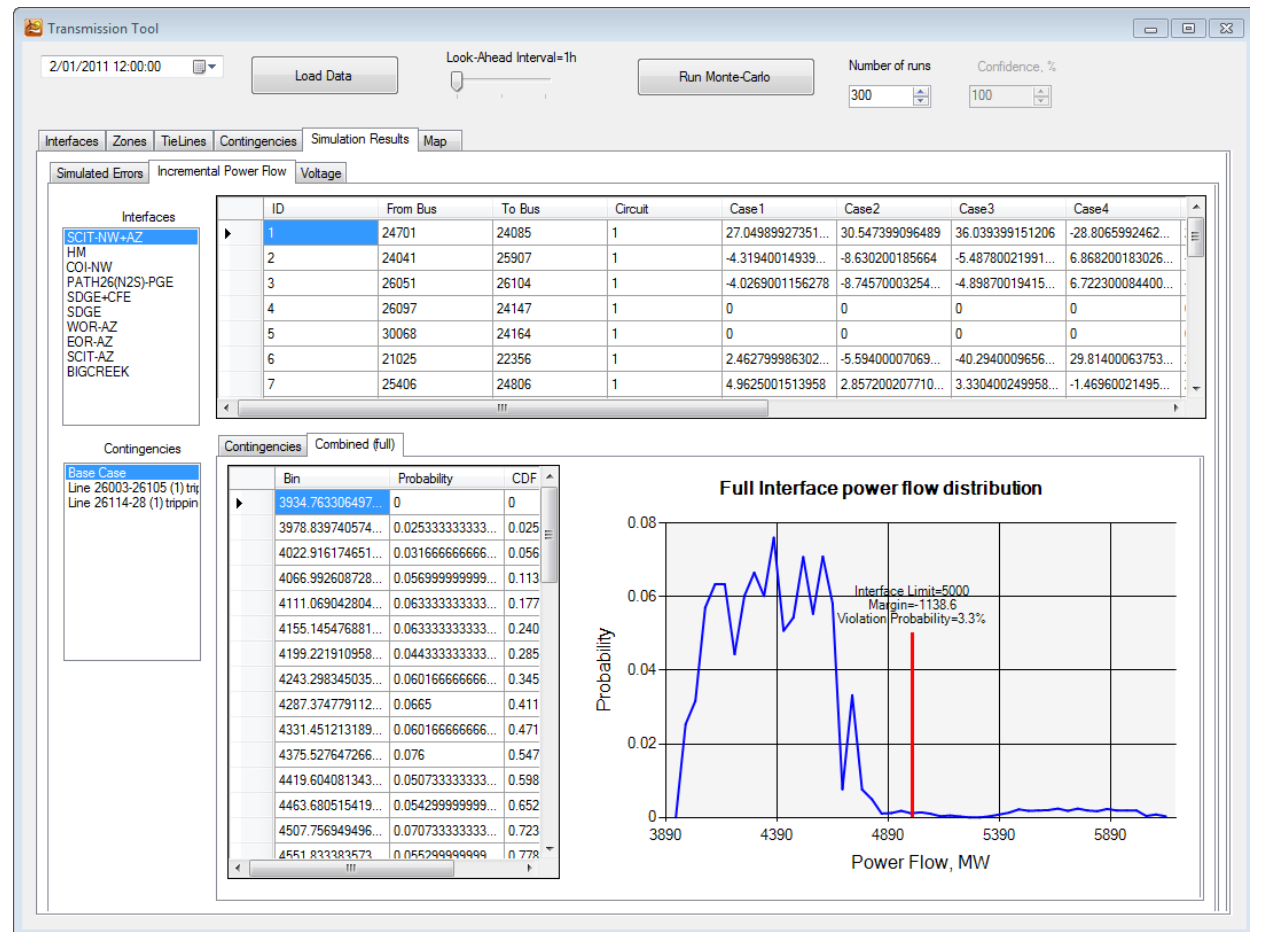


Figure 2 shows a conceptual design of visualization display based on Google Earth technology. Congested transmission interfaces and buses with potential voltage problems can be highlighted on the Google Earth display. Depending on probability of transmission and voltage limits violation, different colors can be used. Three-dimensional bars and cylinders can be used to show the size and probability of transmission congestions or voltage stability problems.

\section{Figure 2: Conceptual Design of the Visualization Display Based on Google Earth Technology}

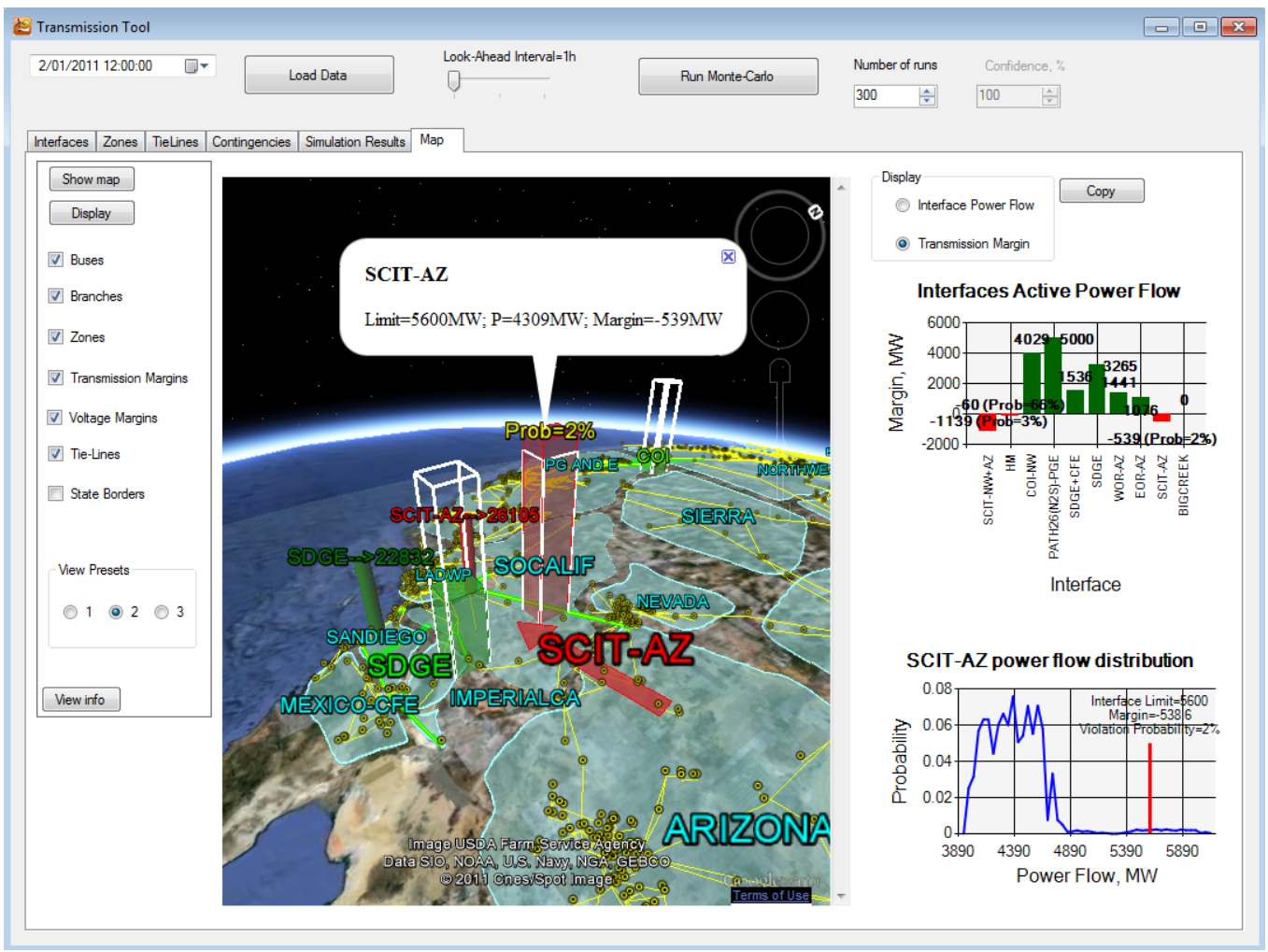

To summarize this work, in this report, the development of a transmission tool on the prototype level is presented. The methodology, design consideration, system architecture, simulation results, and graphical user interface (GUI) are described. The power system model and the methodology to determine and probabilistic thermal congestion limits based on power transfer distribution factor are presented. The five key system modules, e.g., power flow module, power transfer distribution factors (PTDF) module, forecast error module, probability congestion module and interface module are also discussed in the report. Currently, the developed transmission tool is in a prototype level based on a simplified model and data. Future work could be to install and test the tool in a real control center using actual system model and data.

The use of specific vendors or equipment in this document is for research purposes only, and does not constitute an endorsement. 


\section{CHAPTER 1: \\ Introduction}

\section{Business Need}

The "CAISO Integration of Renewable Resources: Operational Requirements and Generation Fleet Capability at 20\% RPS" report published in August 2010 noted that the "integration of variable energy resources will require increased operational flexibility - notably capability to provide load-following and regulation in wider operating ranges and at ramp rates that are faster and of longer sustained duration than are currently experienced." Uncertainties in forecasts of intermittent generation and load make this integration considerably more complex.

Interacting wind, solar, and load forecast errors can create significant unpredictable impacts on the transmission system, congestion, voltage and reactive power stability margins. For instance, the worst case can be a combination of the significant positive errors in one area of the power system interconnection with the significant negative errors in another area. This event can lead to the significant deviation of power flow from the scheduled values, and thus create the congestion and voltage stability problems. These impacts will be increasing with the increasing penetration levels of variable renewable generation in the Western Interconnection and California power systems. To maintain a secure system reliability level, the probability and the magnitude of the impacts should be evaluated and communicated to the system operators. Based on this information, the system power flow limits, dispatches, voltage levels, and available reactive power margins could be adjusted to minimize the risk of system problems and failures to an acceptable level whenever it is required.

Currently California Independent System Operator's (ISO's) vendor software determines thermal congestion and voltage stability margins for a number of selected transmission paths and contingencies. However, this analysis is based on a deterministic model and does not take into account the probabilistic nature of the variable generation. This analysis does not show the probability and magnitude of possible transmission violations caused by random deviations of system parameters from their forecasted values. To assist California ISO in making operational decisions that minimize reliability concerns arising from the lack of predictability of renewable intermittent resources, Pacific Northwest National Laboratory (PNNL), in conjunction with California ISO, developed a tool for predicting and displaying the operational transmission impact of forecast uncertainties.

Based on recommendation of the California ISO project support team, a decision was made to ensure connectivity to the analytical tool being developed by PNNL with the tools already installed and used by the California ISO. In the course of this project, the California ISO has implemented a real-time voltage stability analysis (RTVSA) tool, and advanced visualization and data processing tools. In this situation, the project priorities and scope have been changed by California ISO. Developing a standalone fully- functional transmission tool (TT) would be redundant. Based on recommendation of the California ISO project support team, a decision was made to develop a TT prototype and its integration approach with the tools already installed and used by California ISO. 
The software tool is expected to utilize the results of real-time voltage stability analysis tool. The output of the PNNL tool is expected to be displayed in a control room by California Independent System Operator (CAISO) visualization software.

\section{Objectives}

The objective of this work is to develop a prototype tool to identify transmission problems, posed by the intermittency and variability of wind and solar generation, 1 to 3 hours ahead of time, and inform operators on potential risks for the purposes of early warning and preventive control. As noted before, the scope is limited to developing a prototype tool that implements and demonstrates the main developed methods and models, and fully illustrates the advantages of PNNL's methodology.

The analyzed system impacts include:

1. Impacts on congestion;

2. Impacts on voltage and transient stability margins, and

3. Impacts on voltage reductions and reactive power margins.

The impacts are analyzed in the base case and under all user-specified contingencies, so that the most limiting contingency is determined and addressed.

The developed methodology and prototype software should provide the following features:

1. Better quantification of available security margins. Based on a statistical analysis of multiple forecast errors, the tool should provide an opportunity to adjust security margins depending on the risk (expected size and probability) of potential transmission violations.

2. Better reliability. By adjusting the system security margins on critical paths in the system, the tool should help to prevent potential violations caused by random variations of system load and variable generation around their forecasted values.

3. Better utilization of transmission assets. In cases when the deterministic security margin is excessive, the tool should provide recommendations to reduce this margin based on the actual variability of the flows in the analyzed critical paths.

4. Better situation awareness and predictive system monitoring. System dispatchers should be informed about potential violations and associated risks on all critical paths in the system, and on the most critical contingencies as well as the expected time to violations.

5. Preventive control. The TT algorithm should provide time for decision-making and selection of mitigation measures to reduce the expected size and probability of violations to an acceptable level.

This report focuses on probabilistic assessment and visualization of stability margin, voltage levels, reactive power reserves, and transmission congestion caused by random factors including renewable generation. This is one of the two tools developed in this project. The other 
tool - the "ramping tool" - focuses on probabilistic assessment of generation and ramping requirements needed for intra-hour balancing purposes and is described in a separate report.

Based on California ISO input, the ramping tool was given a higher priority and therefore a higher share of the project resources. The transmission tool scope is therefore limited to developing a prototype of the tool that demonstrates the main capabilities. Further development and integration with vendor-supported software (such as real-time voltage stability analysis software and CAISO visualization software for displaying purposes) at California ISO are necessary for a practical deployment, and they are not addressed in this document.

This report enables the California ISO technical staff and management to evaluate the need for a fully developed tool. It is, therefore, important to note the capabilities of the prototype that has been developed in relation to the capabilities of the fully developed system. 


\section{CHAPTER 2: Real-Time Voltage Stability Analysis Software Description and Connectivity Issues}

Since the beginning of the project, the California ISO has implemented a RTVSA tool, and advanced visualization and data processing tools. In this situation, the project priorities and scope have been changed by California ISO. Developing of a standalone fully functional transmission tool would be redundant. Based on recommendation of the California ISO project support team, a decision was made to develop a TT prototype and its integration approach with the tools already installed and used by California ISO. The connectivity issues are addressed in this report from the methodology and system model perspective to provide future connectivity of the future industry-grade applications with the California ISO systems generally, and with the real-time stability analysis applications, as well as with the CAISO visualization tools.

\section{Description of the RTVSA Methodology}

CAISO real-time operations have implemented a RTVSA tool and corresponding wide-area visual displays to manage the voltage and reactive power resources on the transmission system and to identify the following related characteristics (Varghese et al. 2008):

- Voltage security margin calculation;

- Worst-case contingencies leading to voltage collapse;

- Abnormal reductions of nodal voltages;

- Contingency ranking by margin to voltage collapse;

- System conditions with insufficient stability margin;

- Weakest elements within the grid, and

- Two-dimensional nomograms.

\section{Some Algorithmic Details}

The RTVSA algorithmic details include the following (Varghese et al. 2008):

- Continuation power flow(CPF);

- Voltage stability indices;

- Routes to voltage collapse;

- Preventive and enhancement control;

- Detection of insecure contingencies;

- Identification of critical contingencies;

- Preventive control against insecure contingencies;

- Enhancement control for critical contingencies, and

- Nomogram computation algorithm. 


\section{Continuation Power Flow}

CPF is a powerful tool to simulate power system steady-state stationary behaviors with respect to a given power injection variation scenario. Power injection variations include both load variation and real generation scheduling in power systems. This tool has been implemented in several commercial packages for generating P-V curves. CPFLOW methods have been studied extensively in power system (Varghese et al. 2008).

\section{Contingency Analysis}

CAISO developed inputs to RTVSA to define interfaces and other flows to monitor, three severe $\mathrm{N}-2$ contingencies and their associated RAS scripts, a N-1 contingency list and voltage limit and thermal limit monitoring lists (Varghese et al. 2008).

More details about the RTVSA methodology can be found in Chiang et al. (2009).

CAISO RTVSA Architecture and Information Flow (Varghese et al. 2008)

The CAISO RTVSA project can be broken down into several components as specified below.

1. Network model and supplemental data

2. Dynamic input data and interface

3. Modules and results overview

4. Output data interface.

Network Model and Supplemental Data (Varghese et al. 2008)

The RTVSA application uses the same operational model that is used for the power system applications in the energy management system (EMS). This operational model is of nodebreaker CIM/XML format and contains a detailed system configuration and a simplified bulk system (161 kV and above) representation for the Western Electricity Coordinating Council (WECC) region. On a periodic basis, changes to system configurations are updated into this model. For every periodic update (several in a given year), the new model, in CIM/XML format, is imported into the RTVSA application.

The supplemental data files include data related to stress patterns, interfaces, contingencies, remedial action scheme models, tuning parameters for control/corrective actions, and monitored equipment list.

Dynamic Input Data and Interface (Varghese et al. 2008)

This section describes the data associated with changes in the system conditions and requirements. The dynamic data used are

1. Real-time system condition

2. Study base cases (user setup)

3. Load forecast

4. Outage schedules. 
In the EMS system, the State Estimation executes every minute followed by an automated power flow execution prior to the dynamic CIM/XML export.

The load forecast data for the different sub-control areas are obtained from a neural networkbased forecasting tool that will publish the hourly load forecast.

Results Overview (Varghese et al. 2008)

The results of the RTVSA are presented to the control room personnel through two overview displays, respectively - see Figure 3. It is proposed to have a geographic layout of the control area over which the color-coded results of RTVSA modules are presented. The users have the ability to drill down -to displays with more granularities from the overview displays.

\section{Figure 3: The Current Transmission Paths Used by RTVSA Tool and Their Status Monitors} (Salem-Natarajan et al. 2008)

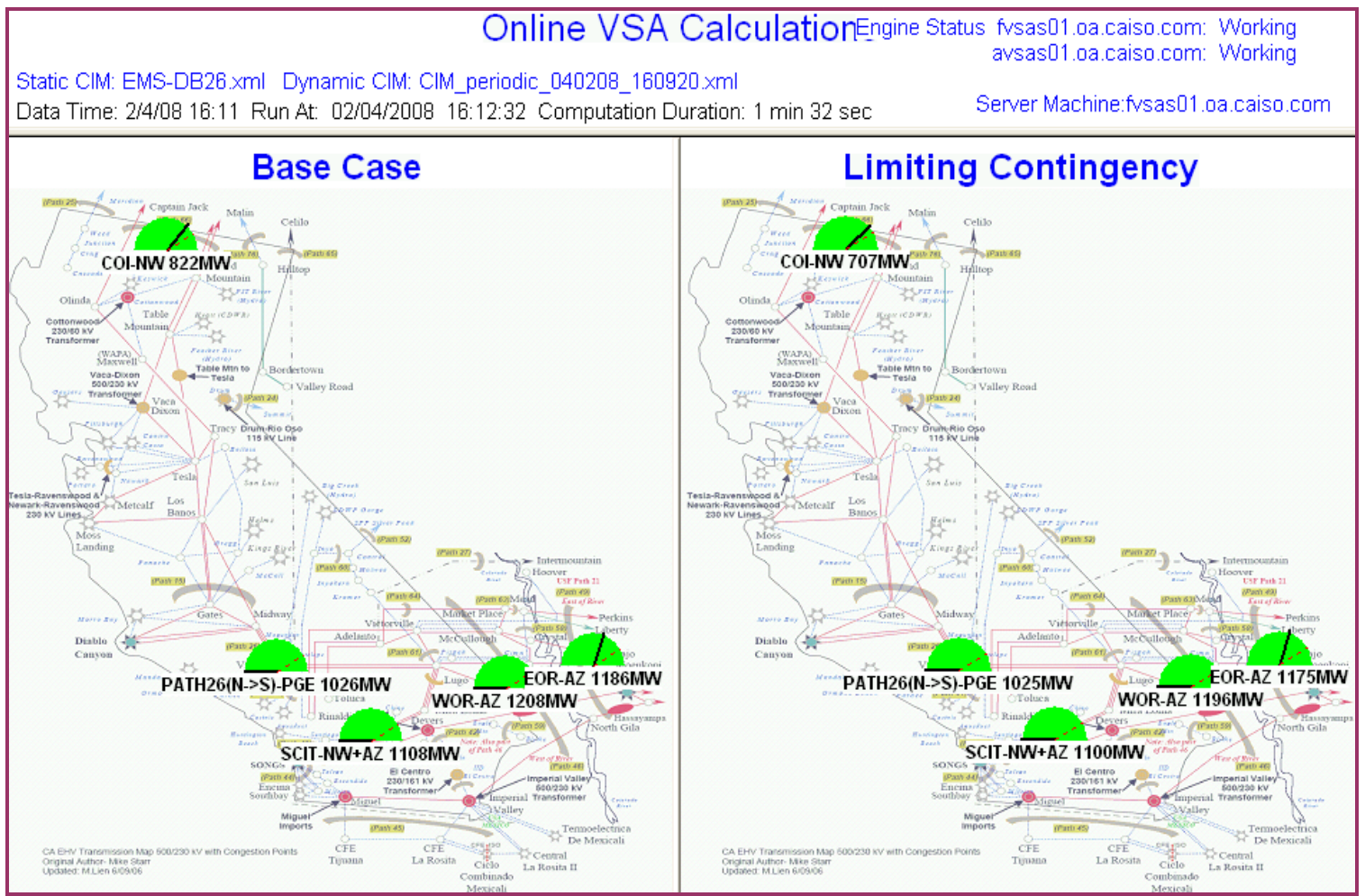

Output Data Interface (Varghese et al. 2008)

In the initial implementation, the results from the RTVSA system are made available for transfer to a data historian system.

The RTVSA implementation at CAISO involves implementing the RTVSA system and specific interfaces for input and output data. The schematic of the different systems involved is presented in Figure 4, where the boxes numbered 1 through 8 refer to the various data pieces 
that can be used as input for the different RTVSA modules and, for these items, the value in parenthesis represents the update frequency for the data.

Figure 4: RTVSA Architecture (Varghese et al. 2008)

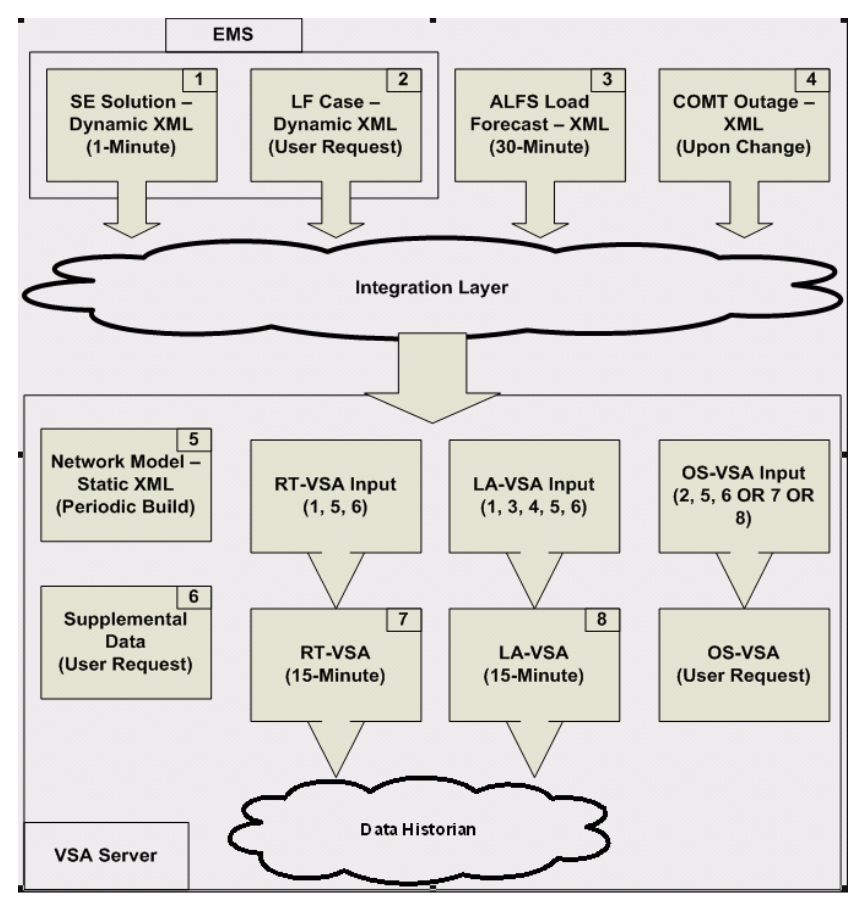

\section{Definitions and Output Parameters}

This section outlines definitions used in the RTVSA tool. These definitions are reproduced in this report because they are adopted without change in the transmission tool as a result of connectivity issues.

\section{Generation Dispatch}

The RTVSA tool implements its own generation redispatch under contingency conditions and to simulate system stress. Details of these algorithms are not known.

\section{Stress Patterns}

To stress each interface, the RTVSA algorithm determines certain stress patterns, which is an approach to change load and generation to increase the power flow in this interface. Details of the algorithm are not known, and apparently have not been published yet.

\section{Load Margin}

Import (Load Margin) is the maximum total real power transferred from source to sink before the system hits the voltage collapse point under a proposed stress pattern. In this regard, import is the same as load margin. In the voltage stability analysis (VSA) viewer and study mode VSA, import always means load margin. Note that $\mathrm{P}_{\text {import }}$ along the $\mathrm{x}$-axis of the P-V curves shown 
below denotes the value of the real power imported from source to sink as the system is being stressed. The nose point of this "import" curve is the system load margin to voltage collapse (Varghese et al. 2008).

Load margin corresponds to the maximum total real power transferred from source to sink before the system hits the voltage collapse point under a proposed stress pattern (SalemNatarajan et al. 2008). The voltage stability analysis and enhancement (VSA\&E) load margin calculation determines the voltage stability margin in megawatts (MW) and megaVAr, between the voltage collapse point and the current power system operation point (Bigwood Systems, Inc. 2012).

\section{P-V and Q-V Curves}

P-V curves, Q-V curves, or P-Q-V curves are used to analyze power system behavior under varying loading conditions. The nose point of these curves provides information for various power system analysis such as voltage stability analysis and loadability analysis (Varghese et al. 2008). Figure 5 and Table 1 taken from Varghese et al. (2008) explain how system conditions are analyzed using these curves, and which system characteristics are derived from these curves by the VSA\&E tool under normal and contingency conditions.

Figure 5: P-V Curves and Derived System Characteristics (Varghese et al. 2008)

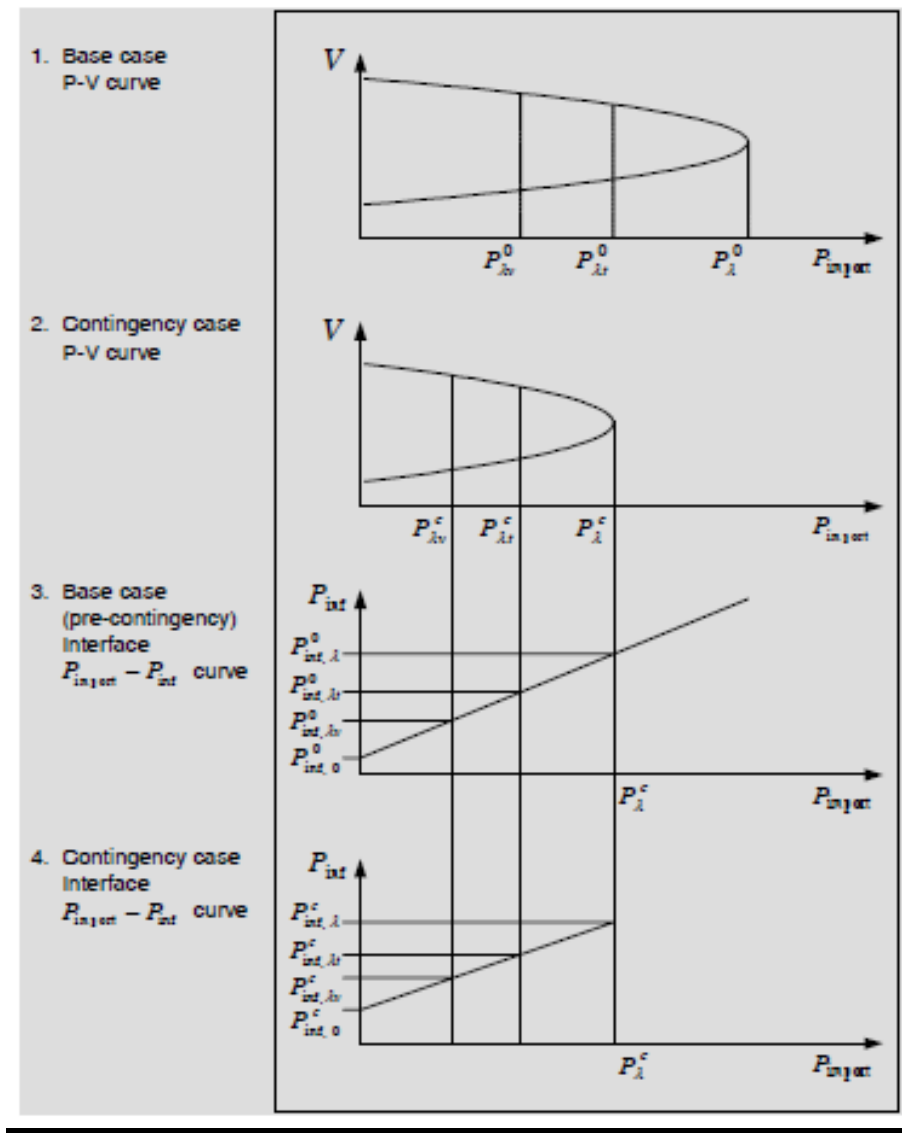


Table 1: P-V Curves and Derived System Characteristics (Varghese et al. 2008)

\begin{tabular}{|l|l|}
\hline $\mathbf{P}_{\text {ingort }}$ & System import value \\
\hline $\mathbf{P}_{\text {inf }}$ & Power flow across the interface \\
\hline $\mathrm{P}_{\lambda}^{0}$ & Base case Load Margin. \\
\hline $\mathrm{P}_{\lambda v}^{0}$ & Base case voltage limit load margin. \\
\hline $\mathrm{P}_{\lambda t}^{0}$ & Base case thermal limit load margin. \\
\hline $\mathrm{P}_{\lambda}^{c}$ & Contingency case Load Margin. \\
\hline $\mathrm{P}_{\lambda v}^{c}$ & Contingency case voltage limit load margin. \\
\hline $\mathrm{P}_{\lambda t}^{c}$ & Contingency case thermal limit load margin. \\
\hline $\mathrm{P}_{\text {inf,0 }}^{0}$ & Base case (pre-contingency) interface flow \\
\hline $\mathrm{P}_{\text {inf,0 }}^{c}$ & Contingency case interface flow without stress. \\
\hline
\end{tabular}

\begin{tabular}{|l|l|}
\hline $\mathrm{P}_{\text {inf }, \lambda}^{c}$ & Contingency case interface flow at $\mathrm{P}_{\lambda}^{c}$ \\
\hline $\mathrm{P}_{\text {inf }, \lambda v}^{c}$ & Contingency case interface flow at $\mathrm{P}_{\lambda v}^{c}$ \\
\hline $\mathrm{P}_{\text {inf }, \lambda t}^{c}$ & Contingency case interface flow at $\mathrm{P}_{\lambda t}^{c}$
\end{tabular}

Figure 6 shows examples of real P-V and Q-V curves (Li et al. 2004).

Figure 6: P-V and Q-V Curves Produced by VSA\&E Tool (Li et al. 2004)

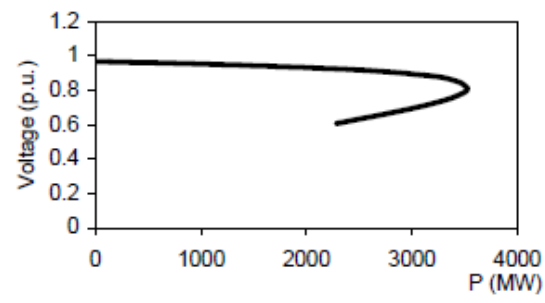

(a) P-V curve

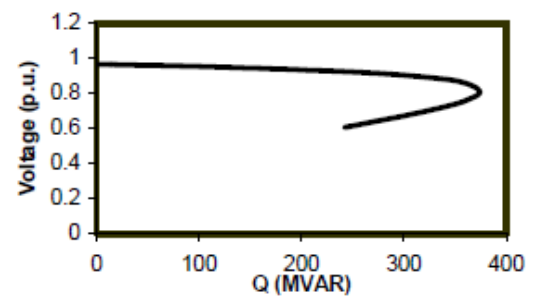

(b) Q-V Curve 


\section{Critical Interface and Deterministic Transmission Limits}

Generally, deterministic transmission limits can be induced by thermal, voltage, voltage stability, and transient stability constraints. A transmission constraint (TC) on a transmission path $i-j$ is denoted as $T C_{i j}$. The usual conditions that are set and monitored for the TCs are as follows:

$$
\begin{aligned}
& P_{i j}^{b} \leq T C_{i j} \\
& \max P_{i j}^{c} \leq T C_{i j}
\end{aligned}
$$

where $P_{i j}^{b}$ and $P_{i j}^{c}$ are power flows through the path i-j in the normal (base case) and contingency situations, respectively. Because the flow in the base case $P_{i j}^{b}$ influences the contingency flows $P_{i j}^{c}$, that is $P_{i j}^{c}=f\left(P_{i j}^{b}\right)$, conditions (1) could be reduced to

$$
P_{i j}^{b} \leq T C_{i j}^{b}
$$

where $T C_{i j}^{b} \leq T C_{i j}$ is an adjusted base case deterministic limit for the base case conditions, selected to eliminate thermal violations on the path $i-j$ for all analyzed contingencies. Figure 7 explains the idea of the adjusted base case deterministic limit $T C_{i j}^{b}$ for the base case condition. If (2) is satisfied, then all contingency conditions (1) will be satisfied as well.

Figure 7: Critical Interface and Deterministic Transmission Limits

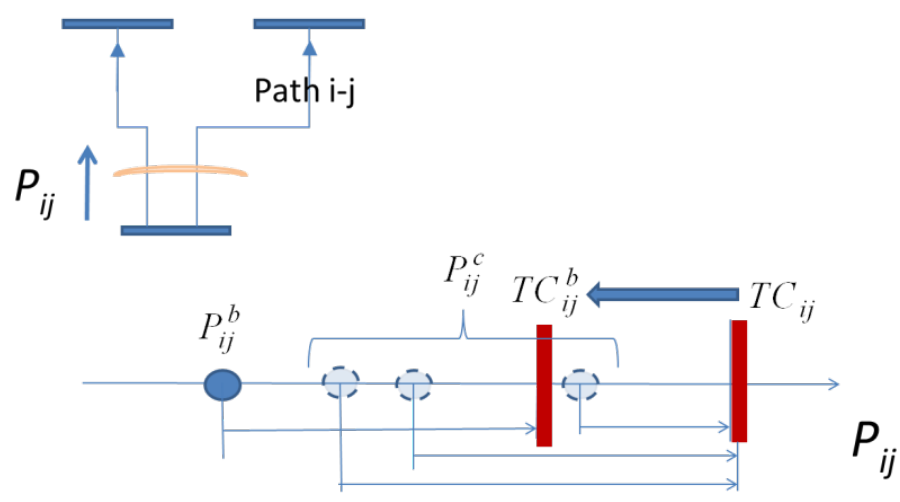

\section{Selected TT-RTVSA Integration Approach and its Implications}

The TT prototype is designed to minimize incremental efforts by taking maximum advantage of existing tools already deployed at the California ISO Control Center, mostly the real-time 
voltage stability analysis and enhancement (VSA\&E) tool and the mapping and visualization tool. This approach, supported by the California ISO, implies the following important consequences to the TT:

(a) The analysis is limited to several critical transmission paths (interfaces), so that all transmission constraints are represented as limits applied to power transfers along these paths. Mutual dependences between power transfers, as well as the limits on different paths, are ignored.

(b) The limits are determined based on certain stress patterns applied to system generation and load. Possible deviations from these patterns, resulting in changing transmission limits, are ignored.

(c) Generation redispatch algorithms are limited to the ones embedded into the RTVSA tool.

(d) Voltage and reactive power changes are reflected using P-V and Q-V curves. Variations of these curves resulting from changing stress patterns are ignored.

(e) The TT has no access to the internal algorithms and information processed by the VSA\&E tool, so the TT algorithm has been designed to process only the input and output VSA\&E information. 



\section{CHAPTER 3: Transmission Tool Outputs and Their Utilization}

The output parameters of our Transmission Tool (TT) are designed to enhance the RTVSA tool by adding the probability dimension to the analysis. Thus, instead of the deterministic load margin, which "is the maximum total real power transferred from source to sink before the system hits the voltage collapse point under a proposed stress pattern," a probabilistic value is calculated. This value is based on the acceptable probability of violations (can be set to zero) and their average and maximum size (can also be zero). If the probabilistic margin is found to be below its deterministic assessment, this indicates that random variations of power in the analyzed interface need to be addressed by an appropriate additional increase of the security margin and by applying additional controls helping to stay away from violations. Similarly, probabilistic voltage reductions and reactive power margins can be evaluated. Details of the proposed probability-based methodology are provided below in the following sections.

The main factor considered in this analysis is the impact of random variations of system load, wind and solar generation from their forecasted values on power transfers in the analyzed transmission paths. These impacts can be revealed by simulating forecasting errors (of different kinds) distributed over a large geographical area. The state space model developed for this purpose presented in Makarov et al. (2010). Errors caused by variability (deviations from flat energy schedules) are also simulated. Based on this model and an incremental linearized model reflecting the impacts of system imbalances on power transfers, by repeating simulations of random forecast errors and the corresponding increments of monitored flows, we determine the probability distributions of the flows. These distributions are used to find the probabilistic load margin. Also, these distributions and P-V and Q-V curves computed by VSA\&E - RTVSA tool are used to determine probability distributions of the voltage magnitudes and reactive power margins.

\section{Probability Distribution of Transmission Flows}

In this project, a probabilistic approach is applied, where the probability of violating the preset transmission limit, as well as the average and maximum size of violation will be evaluated. Random factors contributing to this possible violation include random unpredicted variations of wind, solar generation and system load. Their model will be described below. Similar to a deterministic approach, the analysis will be conducted for a specified set of contingencies.

The probability distribution of transmission flows can be obtained by multiple Monte Carlo runs, where the power mismatches caused by forecasting errors and variability in different parts of the system are simulated repeatedly using the state-space and variability models described below in this report. Resulting power flow variations in the analyzed transmission paths are obtained with the help of linearized incremental power flow model and power transfer distribution factor (PTDF) factors as described below.

This section describes how the probability distribution of these flows can be obtained (the probability distribution - PDF, and cumulative distribution - CDF functions). 
Because the flows can demonstrate certain mutually correlated and non-parametric statistical behaviors, it is important to select an adequate form of representing the PDF and CDF functions. The analytical form (based on certain known distributions, e.g., normal distribution) hardly serves this purpose. The flow distributions can also demonstrate certain autocorrelation, especially between short subsequent dispatch intervals. That is why multidimensional histograms were selected for this work as an approach to describe the multidimensional distributions of power flows on multiple critical paths of the system.

Figure 8 gives an example of a system part, where two critical paths are shown, $P_{i j}$ and $P_{m n}$. Variations of power transfers in interfaces $i-j$ and $m-n$ are caused by wind generators $W G_{p}$, $W G_{q}, \ldots$ and loads $L_{\mathrm{i}}, L_{\mathrm{k}}, \ldots$.

Figure 8: Example Part of a Power System

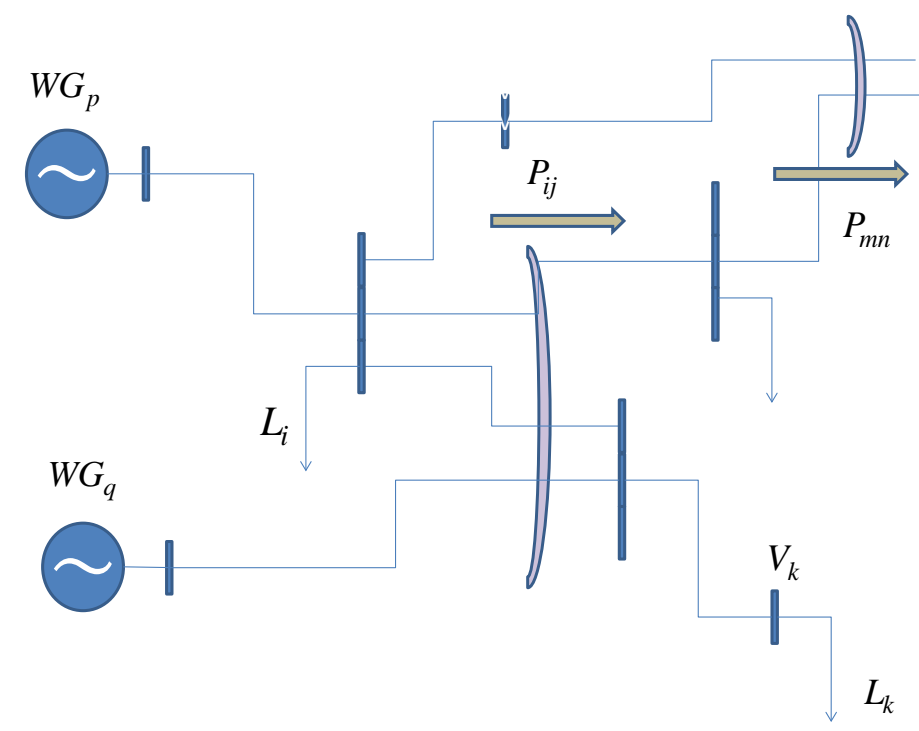

The collective impact of variability and forecast uncertainty from all these resources can be depicted as follows.

\section{Probability of Violation of Transmission Limits}

The user will specify maximum acceptable probabilities of violating transmission limits caused by random variations of uncertain parameters around their forecasts in the base case, $p_{b}^{t}$, and under contingency conditions, $p_{c}^{t}$. In case of limits induced by stability conditions, this probability should be zero. This figure shows a distribution $\operatorname{PDF}\left(P_{i j}^{c}\right)$ of possible values of $i-j$ 
power flow in the most limiting contingency. (PDF stands for the probability density function.) The probability of having a power flow above the limit $T C_{i j}$, corresponding to the most limiting contingency, where $P_{i j}=\max P_{i j}^{c}$, is

$$
p=\int_{T C_{i j} \leq \tau<\infty} P D F(\tau) d \tau
$$

This probability of having the flow above the thermal limit in this contingency should be kept below a user specified level, $p \leq p_{c}^{t}$. If this probability exceeds $p_{c}^{t}$, the power flow in the base case $P_{i j}^{b}$ should be additionally limited by adding a more restrictive limit $T C_{i j}^{b}$ to be enforced during system operation, as shown in Figure 9.

Figure 9: Probabilistic Limits for Base Case Conditions and Contingencies

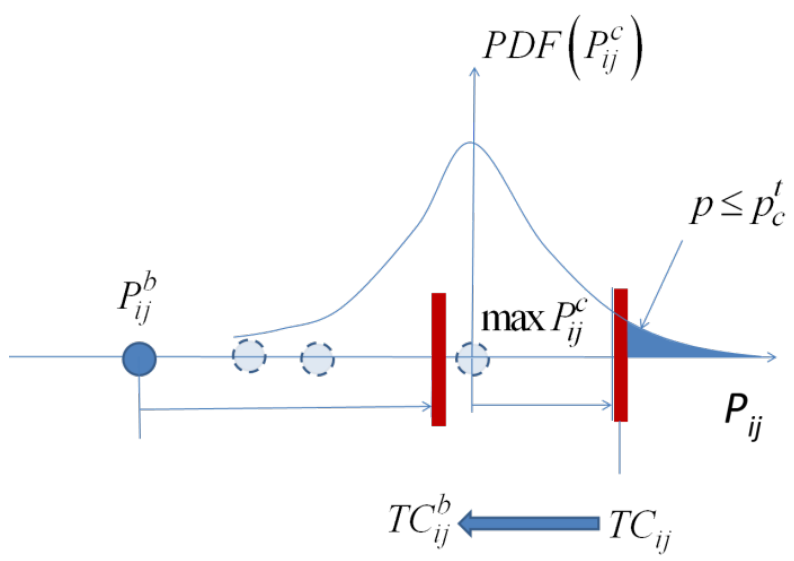

Therefore, the TC-adjustment algorithm will be as follows:

1. Select one of congested transmission paths, $\mathrm{i}-\mathrm{j}$.

2. Calculate PDF functions and probabilities (3) for all contingencies and the base case.

3. Find the most limiting contingency, where the probability of exceeding the transmission thermal constraint is greater than its acceptable value, $p_{c}^{t}, p>p_{c}^{t}$. If, for all analyzed contingencies, $p \leq p_{c}^{t}$, go to step 7 .

4. Adjust the base-case loading on path $\mathrm{i}-\mathrm{j}$, by the value $\Delta P_{i j}$, which makes $p \leq p_{c}^{t}$ in the most limiting contingency.

5. Check if the adjustment works for all remaining contingencies, so that $p \leq p_{c}^{t}$. If, for some contingencies, the probability of violation still exceeds the limit level $p_{c}^{t}$, increase the adjustment $\Delta P_{i j}$ accordingly. 
6. Adjust the power transfer limit in the base case using $\Delta P_{i j}$.

$$
T C_{i j}^{b}=T C_{i j}-\Delta P_{i j}
$$

7. Check if the probability of exceeding the thermal limit is greater than its limit in the base case, that is, if $p$ is greater than $p_{b}^{t}$ or not. If yes, additionally adjust $\Delta P_{i j}$ and $T C_{i j}^{b}=T C_{i j}-\Delta P_{i j}$.

8. Repeat the procedure for all analyzed transmission paths and contingencies.

A summary of output parameters of the algorithm is provided in Figure 10. When the probability of thermal overloads exceeds its threshold value, say $p_{c}^{t}=0.5 \%$, transmission facilities forming the corresponding path $i-j$ will be highlighted on the system map, and a callout box will appear on the screen near the path. In the box, the most limiting contingency will be displayed, along with predicted probability of an overload in this contingency, expected mean and expected maximum magnitudes of the overload, and the recommended adjusted operating transfer capability (OTC) limit $T C_{i j}^{b}$ that should be obeyed in base-case condition to reduce the probability of overload to an acceptable minimum.

Figure 10: Advisory Information for Probabilistic Assessment of Congested Transmission Paths

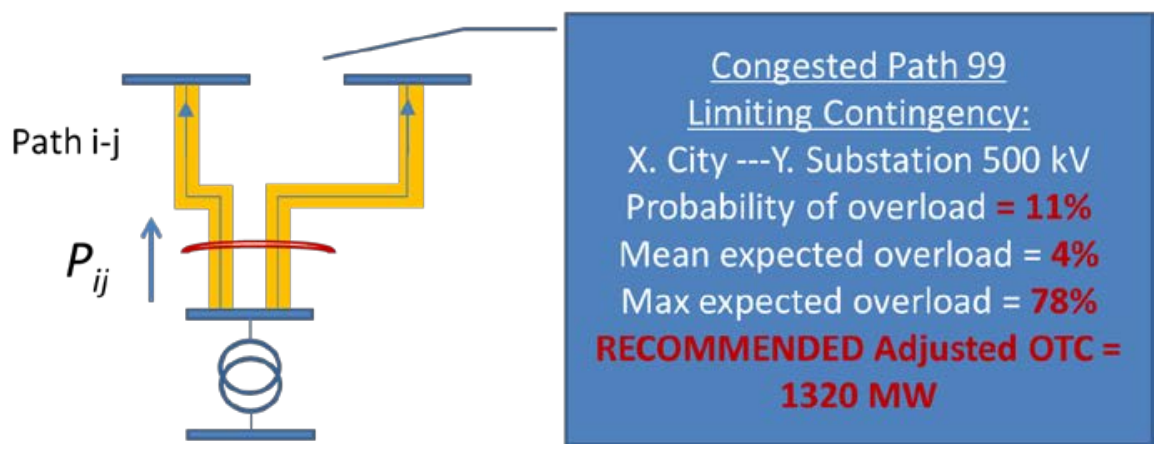

The probability of overload $p$ is calculated using Eq. (3). Note that this is a conditional probability; that is, it is assumed that the contingency has happened already when it is calculated. The mean expected overload $O_{i j}^{c}$ is estimated using Eq. (5), and the maximum overload $O_{i j}^{c}$ corresponds to the maximum power transfer $P_{i j}^{c}=\left.\max P_{i j}^{c}\right|_{P_{i j}^{c}=0}$, where the PDF reaches zero - see Figure 11. 


$$
O_{i j}^{c}=\frac{\int_{T C_{i j} \leq \tau<\infty}\left(\frac{P_{i c}^{c}-T C_{i j}}{T C_{i j}}\right) P D F(\tau) d \tau}{\int_{T C_{i j} \leq \tau<\infty} P D F(\tau) d \tau}[\%]
$$

Figure 11: Mean and the Maximum Overloads

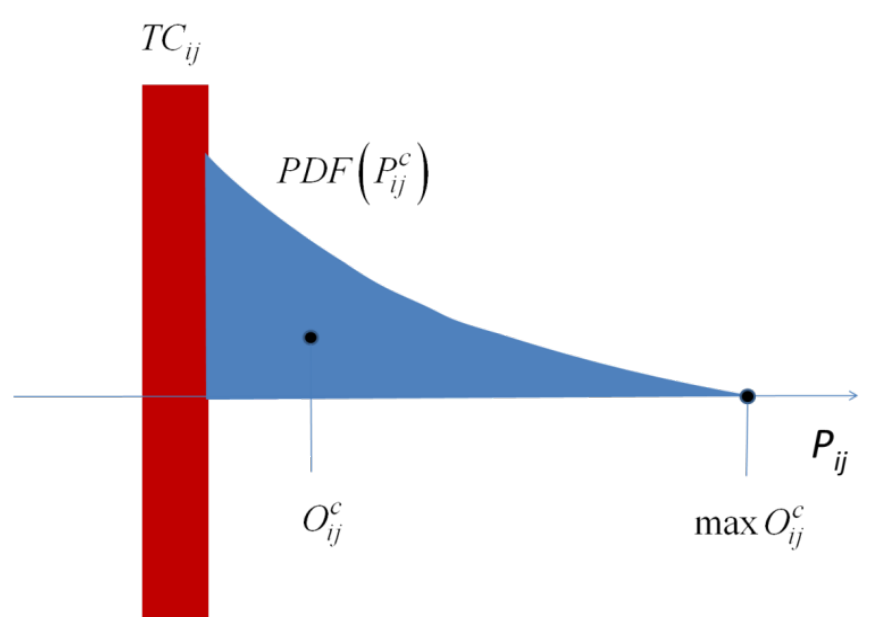

\section{Probability Distribution of Voltage Levels and Reactive Power Margins}

The proposed approach includes $\mathrm{P}-\mathrm{V}$ and $\mathrm{Q}-\mathrm{V}$ curves produced by the RTVSA software tool as described above. The RTVSA tool stresses selected transmission paths one by one by gradual changes of system nodal power injections (generation and load) in certain proportions. For selected buses and selected contingencies, P-V and Q-V curves are produced. They link the power flow in a selected path $P \mathrm{ij}$ with voltage magnitude $V \mathrm{k}$ and reactive power $Q \mathrm{k}$ at selected buses. The same curves can be used to translate PDF functions calculated for the flow $P \mathrm{ij}$. This idea is shown in Figure 12.

In the proposed method, Monte Carlo simulations are used to build a comprehensive probabilistic model and determine TT outputs. For each Monte Carlo run, certain value of $P$ ij is determined. Based on this value and P-V curve, voltage levels $V \mathrm{k}$ at the most important bases $k$ are determined. $\mathrm{Q}-\mathrm{V}$ curves help to link these values with the reactive power injections corresponding to these voltages. Ultimately, through multiple simulations, histograms, PDF and CPF functions can be determined for voltages $V \mathrm{k}$ and reactive power values $Q \mathrm{k}$. The rest of the analysis is similar to the one described above for the probabilistic transmission flows. 
Figure 12: The Idea of Using P-V and Q-V Curves to Obtain Probability Distributions of Voltages and Reactive Power

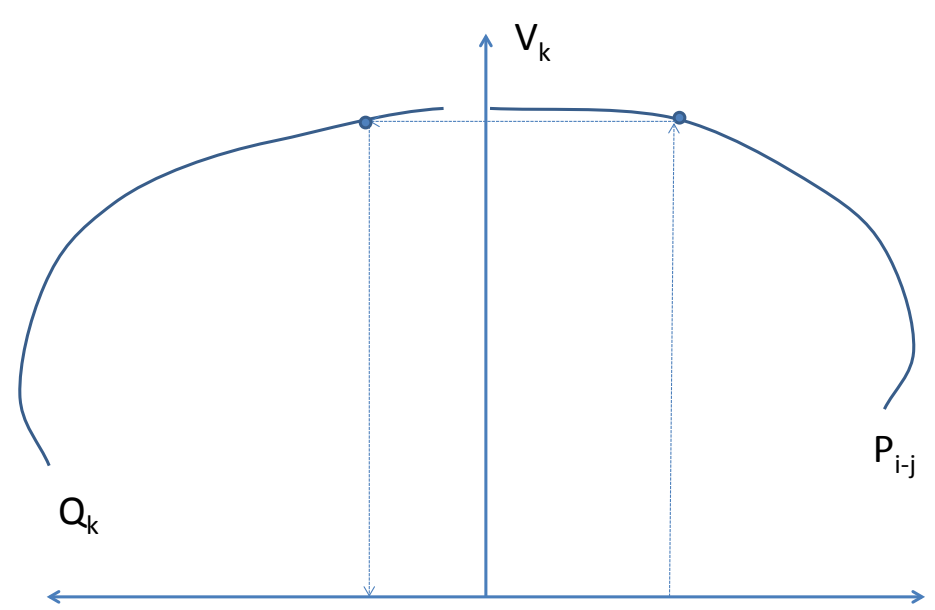




\section{CHAPTER 4: Connectivity with Visualization Software}

Software tools provide advanced visualization capabilities and are widely used at California ISO. Integration of the TT tool developed by PNNL with the existing visualization software will eliminate unnecessary duplication of the effort in this area. Nevertheless, before this integration really happens, PNNL has developed certain prototype displays to demonstrate the performance and features of the TT tool.

Results of the analysis are represented on a map containing the California system or all WECC systems. Two conceptual designs of the map are shown in Figure 13 (conventional map design) and Figure 14 (Google Earth based map design).

In Figure 13, dotted lines represent potentially congested paths, where the average overload or probability of overload exceed their user-specified thresholds. Contours show voltage levels expected in the system.

Figure 13: A Conceptual Screen for Visual Presentation of Transmission Tool Results on a Conventional Map

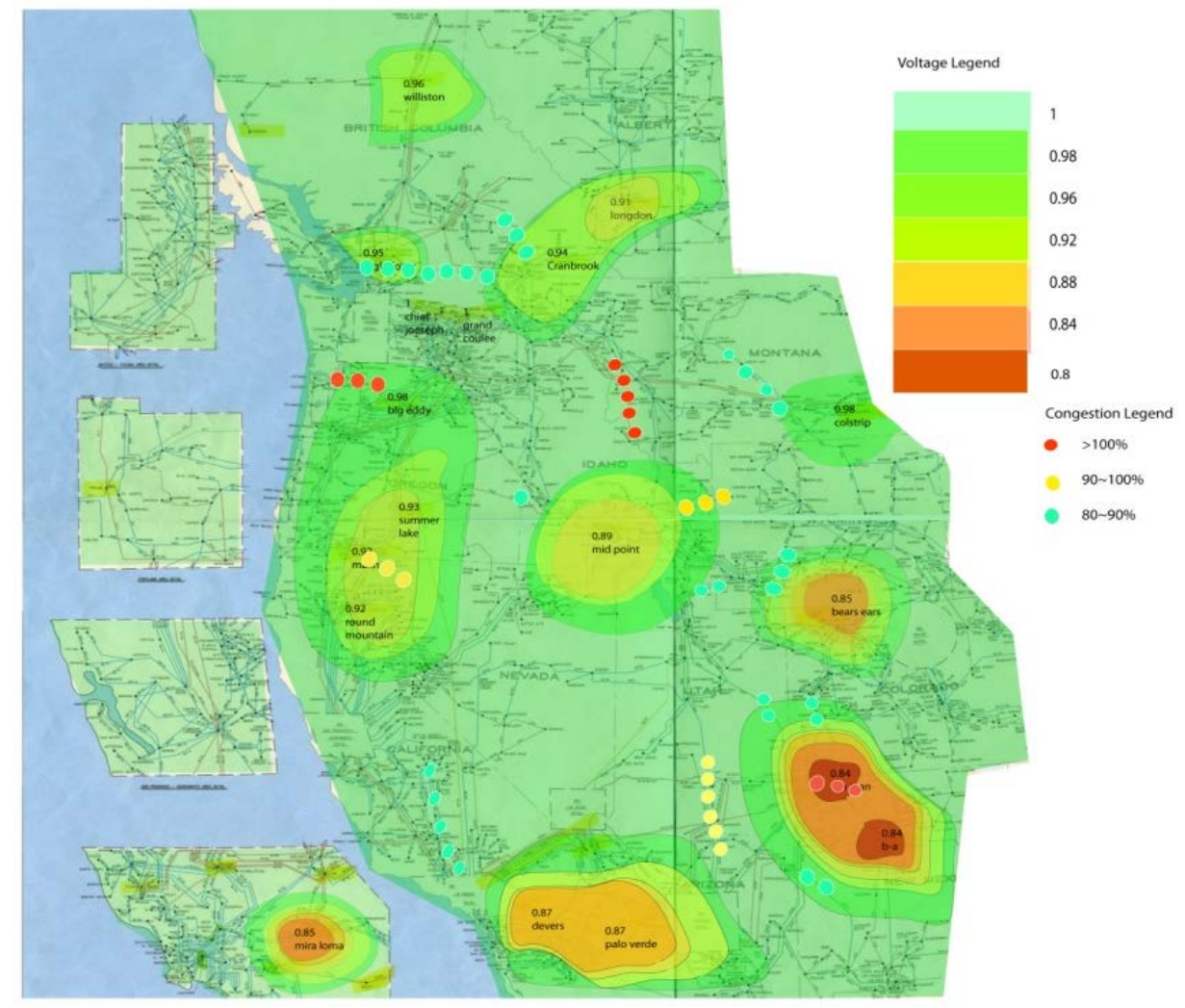


In Figure 14, arrows show congested paths. Congested transmission interfaces and buses with potential voltage problems can be highlighted on the Google Earth display. Depending on probability of transmission and voltage limits violation, different colors can be used. Threedimensional bars and cylinders can be used to show the size and probability of transmission congestions or voltage stability problems. The filling of the bars reflects the expected maximum load on these paths in the most critical contingency. If the probability of overload or the average overload exceed their user-specified thresholds, the filling overflows the bar and its color becomes red.

Real-time dispatchers can select the look-ahead time (up to several hours ahead), specify the alarming threshold probability for system problems and voltage levels, and establish desirable security margins with respect of the maximum overload or minimum voltage level leading to thermal violation, voltage collapse, or transient instability.

Figure 14: A Google Earth Design of the TT Screen

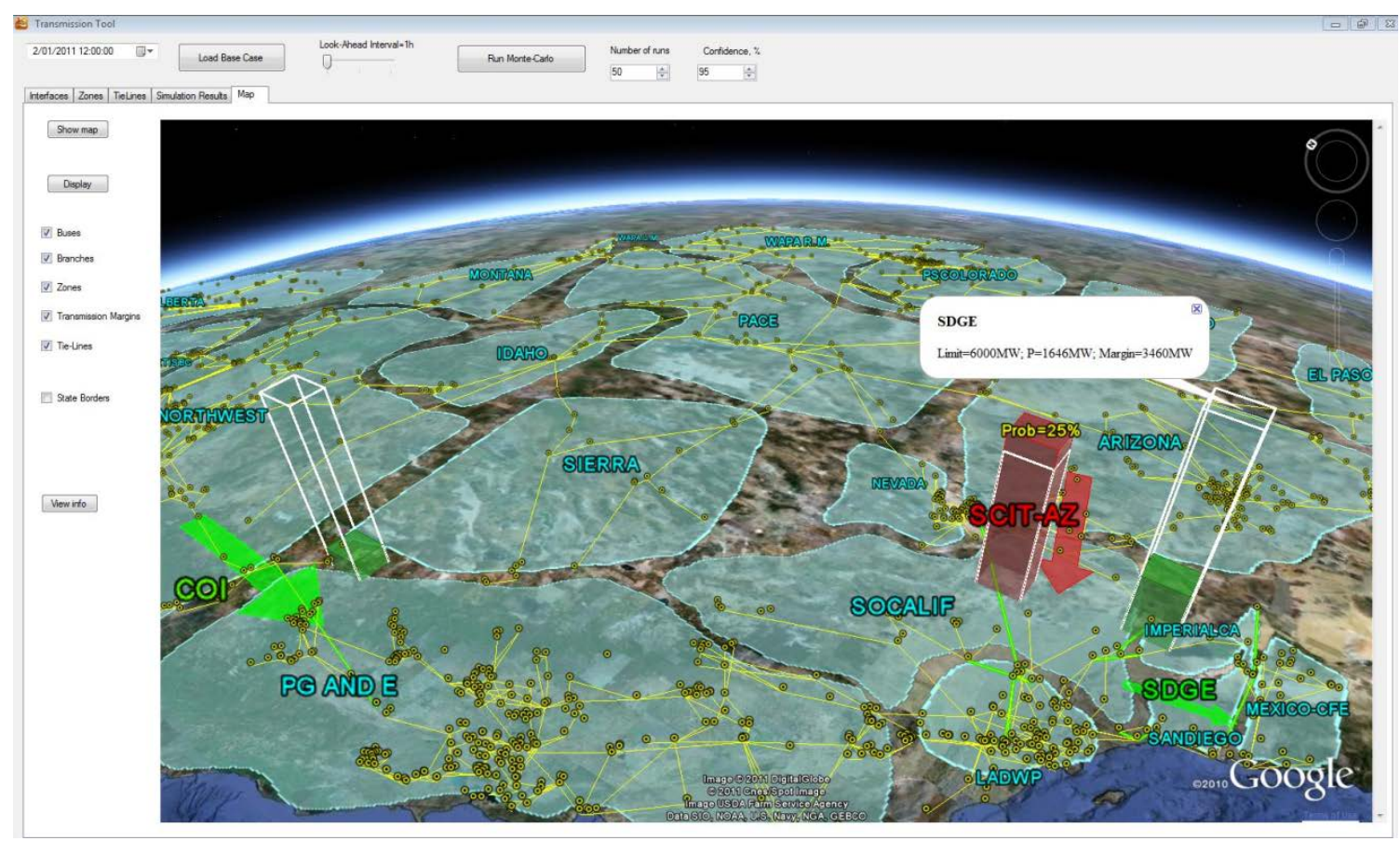




\section{CHAPTER 5: Methodology}

The methodology developed for the TT tool consists of the linearized power system congestion model and state space uncertainty model. The state space uncertainty model is described in detail in Makarov et al. (2010).

\section{Power System Congestion Model}

Figure 15 shows a one-line diagram of congested paths within and around the California ISO control area (Department of Market Monitoring 2007).

Figure 15: Active Congestion Zones and Branch Groups (Department of Market Monitoring 2007)

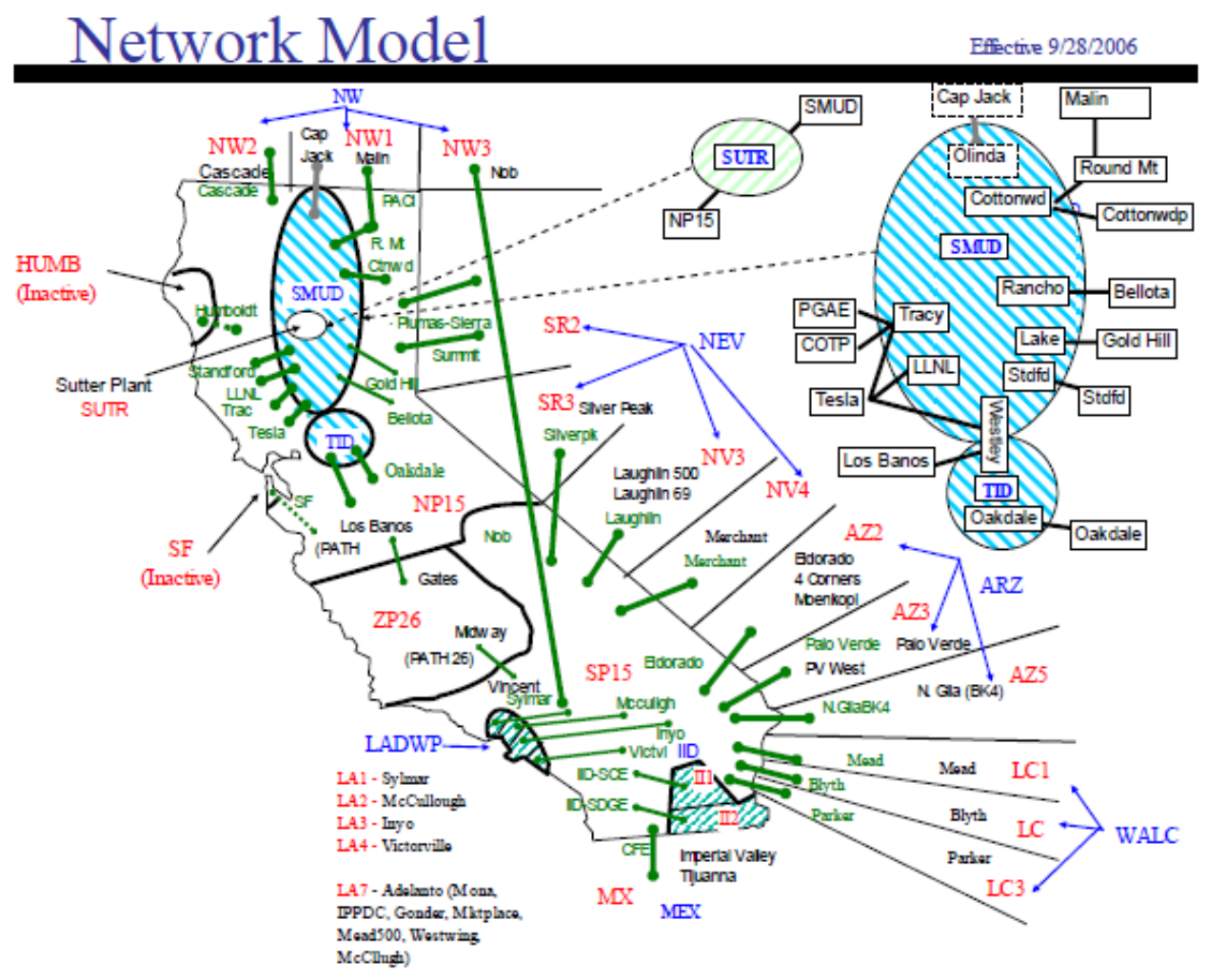

There are nine interfaces in this power system model analyzed by the prototype tool. Table 2 provides a description on these system interfaces and the number of lines in each interface. Interfaces are transmission lines between two control areas (Figure 16). Some major interfaces are monitored and some transmission lines are not. Some control areas have multi-line interfaces between them (see interface 2 between Area 1 and Area 2 in Figure 17). 
Table 2: Interface Description

\begin{tabular}{cc}
\hline Interface & Number of Lines in Interfaces \\
\hline COI-NW & 3 \\
EOR-AZ & 6 \\
HM & 4 \\
PATH26(N2S)-PGE & 3 \\
SCIT-AZ & 26 \\
SCIT-NW+AZ & 26 \\
SDGE & 7 \\
SDGE+CFE & 6 \\
WOR-AZ & 14 \\
\hline
\end{tabular}

Figure 16. Interfaces Between Two Areas

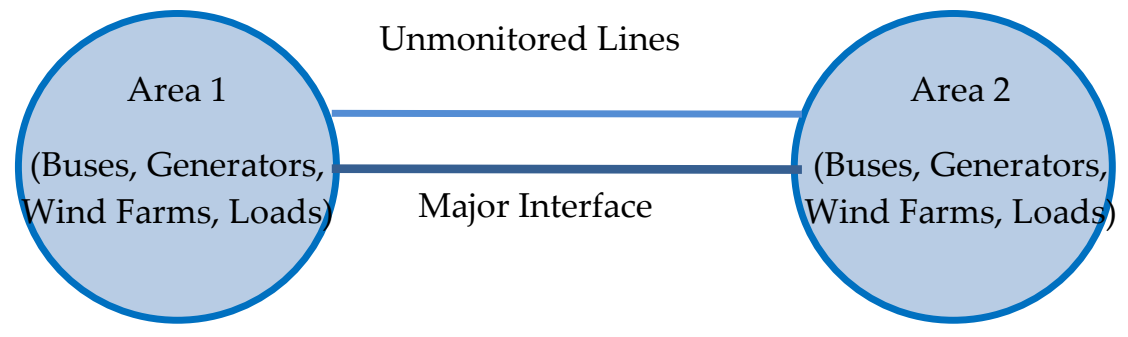

Figure 17. Multi-Line Interfaces Between Areas

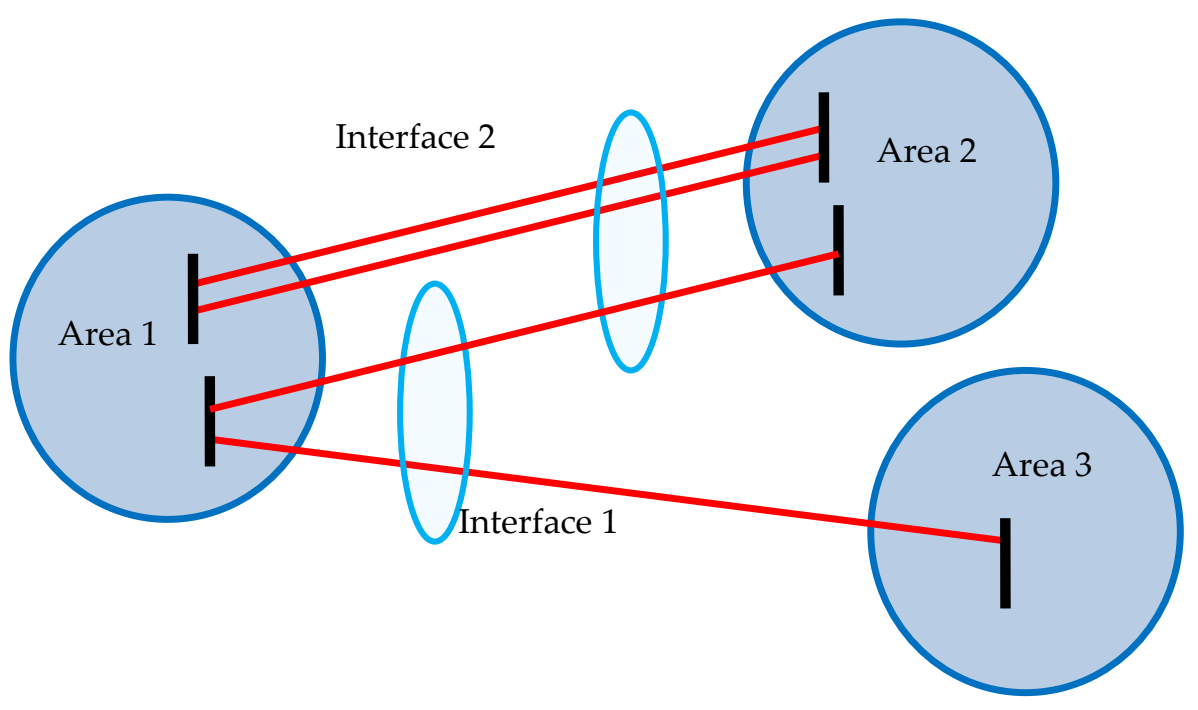




\section{Linearized Incremental Power Flow Model and PTDF}

The system managed by California ISO is a complex one. A description of the system model as it relates to this project is given below. The prototype tool does not address the full complexity of this system model. A simplified linearized version of this full model is used to meet the objectives of this project.

The proposed power flow linearized incremental model is used in this project to evaluate the incremental impacts of wind, solar, and load variability and uncertainty on power transfers in the analyzed paths. The model allows simplifying and speeding up multi-variant computations needed to implement a probabilistic assessment of power transfer and voltage variability using the Monte Carlo method. The incremental analysis is conducted around selected base cases and contingencies produced using the full AC system model. The procedure used to create the incremental model using Power World Simulator software is presented and illustrated in this section using an example of the WECC system model.

In the WECC documents, the term "area" is used to describe regionally aggregated elements of an electric power system. To provide a more specific definition of uncongested areas of the transmission grid and to avoid confusion with the term "control area" (a.k.a. "balancing authority"), we will use the term "zone". Zones are connected through congested interfaces, but there is no congestion within a zone.

The full WECC system model used in the study consists of 15,580 buses, 19,844 branches, and 3,030 generators. A total of 21 zones are defined in the model (Table 3). This structure corresponds to the WECC area structure given by WECC (2007).

Table 3. Zonal Information

\begin{tabular}{cc|cc}
\hline Zone Number & Zone Name & Zone Number & Zone Name \\
\hline 10 & NEW MEXICO & 50 & B.C.HYDRO \\
11 & EL PASO & 52 & FORTISBC \\
14 & ARIZONA & 54 & ALBERTA \\
18 & NEVADA & 60 & IDAHO \\
20 & MEXICO-CFE & 62 & MONTANA \\
21 & IMPERIALCA & 63 & WAPA U.M. \\
22 & SANDIEGO & 64 & SIERRA \\
24 & SOCALIF & 65 & PACE \\
26 & LADWP & 70 & PSCOLORADO \\
30 & PG AND E & 73 & WAPA R.M. \\
40 & NORTHWEST & & \\
\hline
\end{tabular}

In the proposed model, some uncongested zones may belong to several control areas, and some control areas may consist of several zones. 
Figure 18 shows the zonal structure of the WECC system model as provided by WECC (2007). Figure 19 presents the key WECC transmission paths (WECC 2005). Information regarding the operating transfer limits between the zones can be found in the WECC 2008 Path Rating Catalog and other WECC official documents (WECC 2008a, 2008b).

Figure 18: Zonal Structure of the WECC System

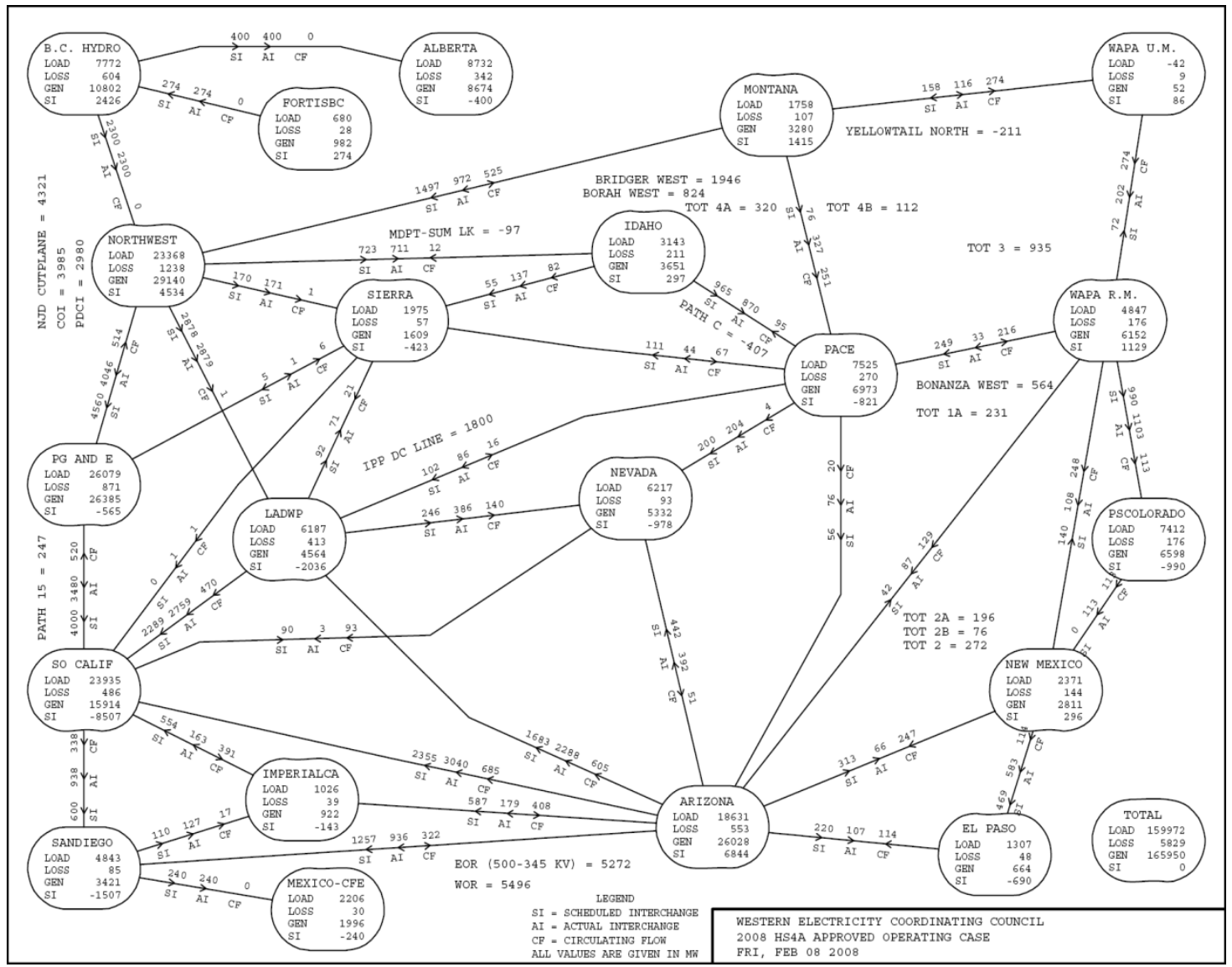

\section{Mathematical Definition of the Incremental Model}

The incremental impact analysis is used to find a relationship between variations of the total zonal active power imbalance and related active power-flow variations in selected transmission interfaces.

The active power-flow variation in the interface between the zones $i$ and $j$ can be calculated as:

$$
\Delta P_{i j}=\sum_{n=1}^{N} P T D F_{n}^{i j} \Delta P_{n}
$$


where $N=$ the number of zones in the system,

$$
\begin{gathered}
\qquad P_{n}=\text { variation of total active power generation in zone } n \text {, and } \\
\operatorname{PTDF}_{n}^{i j}=\frac{\Delta P_{i j}}{\Delta P_{n}} \quad \begin{array}{l}
\text { a power transfer distribution factor reflecting the influence of } \\
\text { generation in zone } n \text { on the power flow in the interface } i-j .
\end{array}
\end{gathered}
$$

Figure 19. WECC System Transmission Lines And Paths (WECC 2005)

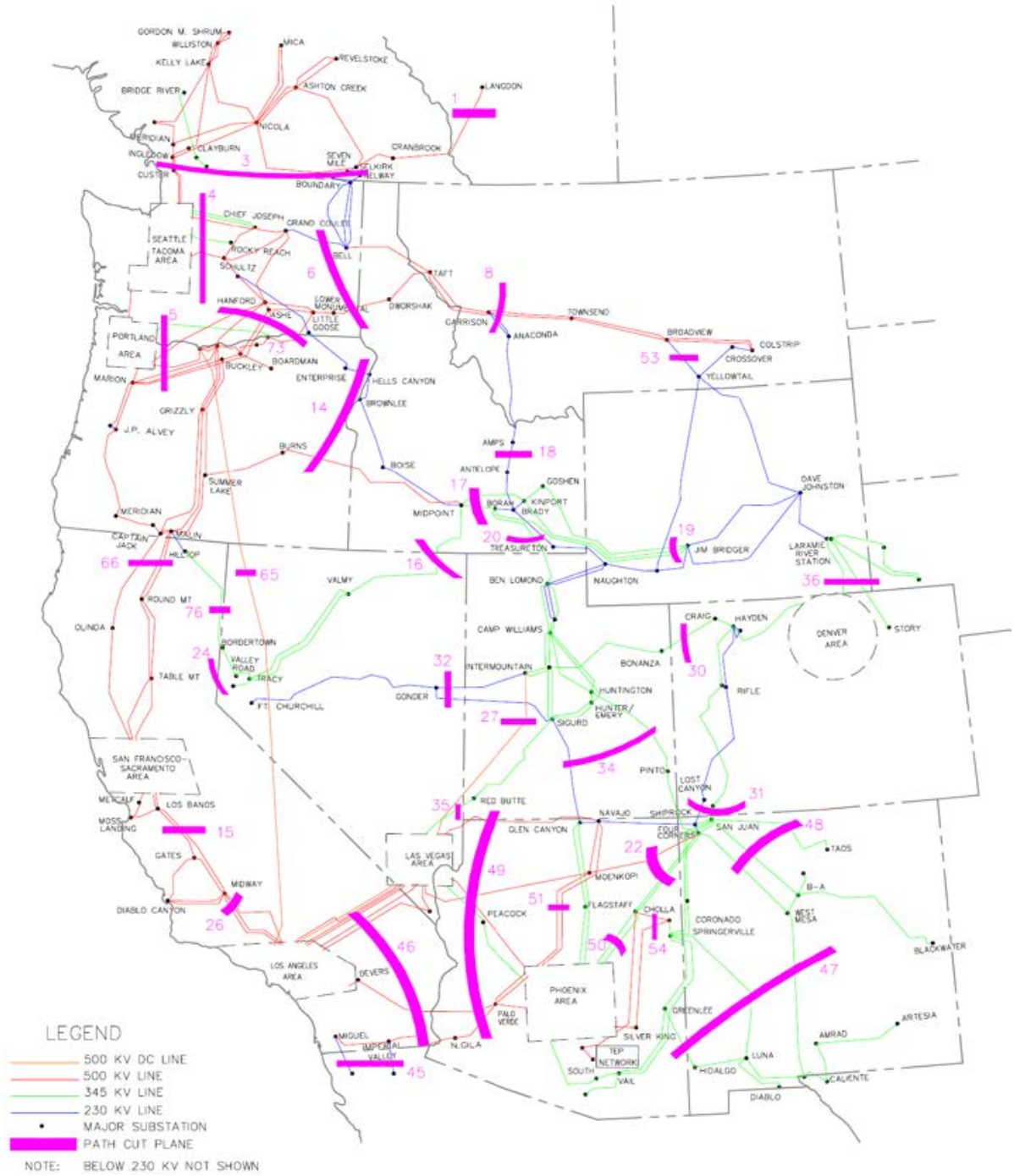




\section{Incremental Model Development Using Power World Simulator}

The Power World Simulator software can be used to create the incremental zonal model of the WECC system. A fragment of the interface PTDFs table calculated for the WECC zonal model using Power World simulator is presented in Table 4.

For example, if generation in the New Mexico zone increases by $200 \mathrm{MW}$, power flow through interface New Mexico - PS Colorado will change by $200 \cdot 0.05=10 \mathrm{MW}$, because the impact of New Mexico zone on New Mexico - PS Colorado interface is equal to PTDF $=5 \%$ (see Table 5).

Table 4: Interface PTDFs (\%)

\begin{tabular}{|c|c|c|c|c|c|c|c|c|c|}
\hline Name & $\begin{array}{c}\text { NEW } \\
\text { MEXICO }\end{array}$ & EL PASO & ARIZONA & NEVADA & $\begin{array}{l}\text { IMPER- } \\
\text { IALCA }\end{array}$ & SOCALIF & LADWP & PG AND E & NORTHWEST \\
\hline $\begin{array}{l}\text { NEW MEXICO- } \\
\text { PSCOLORADO }\end{array}$ & 5 & 2.2 & 1.4 & 1 & 1 & 0.9 & 0.5 & 0.5 & 0 \\
\hline $\begin{array}{l}\text { NEW MEXICO- } \\
\text { WAPA R.M. }\end{array}$ & 7.8 & 8.1 & 6.3 & 4.3 & 4.3 & 4.1 & 1.7 & 2.1 & -0.2 \\
\hline $\begin{array}{l}\text { EL PASO-NEW } \\
\text { MEXICO }\end{array}$ & -19.2 & 30.8 & 1.4 & 0.5 & 0.7 & 0.6 & 0.2 & 0.3 & 0.1 \\
\hline $\begin{array}{l}\text { ARIZONA-NEW } \\
\text { MEXICO }\end{array}$ & -69.9 & -25.1 & 8.3 & 6.6 & 6.3 & 6.4 & 3.9 & 4.4 & 1.9 \\
\hline ARIZONA-EL PASO & -19.4 & -72.2 & 2 & 1 & 1.2 & 1.1 & 0.7 & 0.9 & 0.6 \\
\hline ARIZONA-NEVADA & 1.9 & 3 & 5.7 & -44.5 & 4.6 & 3 & 0.8 & 1.7 & 0.7 \\
\hline $\begin{array}{l}\text { ARIZONA- } \\
\text { IMPERIALCA }\end{array}$ & 0.7 & 0.8 & 2.1 & 0.7 & -21.6 & -0.7 & -0.1 & -0.3 & -0.2 \\
\hline ARIZONA-SANDIEGO & 6.7 & 8.2 & 9.6 & 3 & -7.1 & -5.3 & -0.2 & -1.2 & -0.3 \\
\hline ARIZONA-SOCALIF & 25.4 & 29 & 29.7 & -2 & -12.3 & -15.8 & -7.3 & -11.8 & -8 \\
\hline ARIZONA-LADWP & 19.5 & 24 & 29.2 & 13.3 & 7.7 & -11.2 & -11 & -12.5 & -9.2 \\
\hline ARIZONA-PACE & 11.8 & 12 & 10 & 5.1 & 5.9 & 4.9 & -3 & 0.4 & -3.6 \\
\hline ARIZONA-WAPA R.M. & 2.4 & 3.1 & 3.2 & 2.2 & 2.2 & 2.1 & 1 & 1.2 & 0 \\
\hline NEVADA-SOCALIF & 0.6 & 0.8 & 1.1 & 12.2 & 0 & -1.7 & -0.6 & -1.4 & -0.9 \\
\hline NEVADA-PACE & 0.6 & 1.6 & 3.8 & 6.7 & 4 & 4.3 & -0.8 & 1.4 & -1.4 \\
\hline $\begin{array}{l}\text { MEXICO-CFE- } \\
\text { SANDIEGO }\end{array}$ & -1.3 & -1.3 & -1.5 & -1.3 & -1.3 & -1.3 & -1.2 & -1.4 & -1.4 \\
\hline $\begin{array}{l}\text { IMPERIALCA- } \\
\text { SANDIEGO }\end{array}$ & -0.1 & -0.1 & 0.3 & 0.3 & 18.9 & -0.1 & 0.1 & 0.1 & 0.1 \\
\hline IMPERIALCA-SOCALIF & 0.1 & 0.3 & 0.8 & -0.2 & 56.7 & -1 & -0.7 & -0.9 & -0.8 \\
\hline SANDIEGO-SOCALIF & 3.2 & 4.7 & 6 & 0.1 & 8.7 & -8.4 & -3.1 & -4.5 & -3.6 \\
\hline LADWP-NEVADA & 2.5 & 2.8 & 3.2 & -36.4 & 2.9 & 3.3 & 1.3 & 2.3 & 0.9 \\
\hline LADWP-SOCALIF & 13.8 & 17.7 & 22.1 & 46.8 & 2.3 & -16.6 & 61.3 & -17.1 & -12.6 \\
\hline LADWP-NORTHWEST & 0 & 0 & 0 & 0 & 0 & 0 & 0 & 0 & 0 \\
\hline LADWP-SIERRA & 1 & 1 & 0.6 & 0.3 & 0.2 & 0 & 2.4 & -0.9 & -0.9 \\
\hline LADWP-PACE & -1.8 & -1.9 & -1.6 & -1.3 & -1.1 & -0.9 & 24.9 & -0.1 & -0.1 \\
\hline
\end{tabular}

The incremental model approach results were compared with the real full AC power flow model results to validate the accuracy of the incremental model approach. An example of interface power flows calculated using the full system model, estimated using the incremental model, and the estimation errors are given in Table 5. Table 5 also validates the estimation 
accuracy of the incremental model for contingencies. It can be seen that the MW error of the linearized incremental model is very small.

Table 5: Interface Power Flow Validation

\begin{tabular}{|c|c|c|c|c|c|c|c|c|c|}
\hline \multirow[b]{2}{*}{ Interface Name } & \multicolumn{3}{|c|}{ Contingency 1} & \multicolumn{3}{|c|}{ Contingency 2} & \multicolumn{3}{|c|}{ Contingency 3} \\
\hline & $\begin{array}{c}\text { Full } \\
\text { model, } \\
\text { MW }\end{array}$ & $\begin{array}{l}\text { Incremental } \\
\text { model, MW }\end{array}$ & $\begin{array}{l}\text { Error, } \\
\text { MW }\end{array}$ & $\begin{array}{c}\text { Full } \\
\text { model, } \\
\text { MW }\end{array}$ & $\begin{array}{l}\text { Incremental } \\
\text { model, MW }\end{array}$ & $\begin{array}{l}\text { Error, } \\
\text { MW }\end{array}$ & $\begin{array}{l}\text { Full model, } \\
\text { MW }\end{array}$ & $\begin{array}{l}\text { Incremental } \\
\text { model, MW }\end{array}$ & $\begin{array}{l}\text { Error, } \\
\text { MW }\end{array}$ \\
\hline $\begin{array}{l}\text { NEW MEXICO- } \\
\text { PSCOLORADO }\end{array}$ & -91.1 & -91.1 & 0 & -91.2 & -91.1 & -0.1 & -91.1 & -91.1 & 0 \\
\hline $\begin{array}{l}\text { NEW MEXICO- } \\
\text { WAPA R.M. }\end{array}$ & -88.9 & -88.564 & -0.336 & -88.3 & -87.9 & -0.4 & -89.5 & -88.9 & -0.6 \\
\hline $\begin{array}{l}\text { EL PASO-NEW } \\
\text { MEXICO }\end{array}$ & -292.5 & -292.418 & -0.082 & -292.5 & -292.75 & 0.25 & -292.4 & -292.25 & -0.15 \\
\hline $\begin{array}{l}\text { ARIZONA-NEW } \\
\text { MEXICO }\end{array}$ & 113.3 & 113.958 & -0.658 & 109.7 & 107.65 & 2.05 & 115.9 & 117.15 & -1.25 \\
\hline $\begin{array}{l}\text { ARIZONA-EL } \\
\text { PASO }\end{array}$ & 365.9 & 365.992 & -0.092 & 364.2 & 364 & 0.2 & 366.8 & 367 & -0.2 \\
\hline $\begin{array}{l}\text { ARIZONA- } \\
\text { NEVADA }\end{array}$ & 440.5 & 440.574 & -0.074 & 437.5 & 438.25 & -0.75 & 443.6 & 441.75 & 1.85 \\
\hline $\begin{array}{l}\text { ARIZONA- } \\
\text { IMPERIALCA }\end{array}$ & 250.5 & 250.436 & 0.064 & 250.7 & 251.1 & -0.4 & 250.2 & 250.1 & 0.1 \\
\hline $\begin{array}{l}\text { ARIZONA- } \\
\text { SANDIEGO }\end{array}$ & 979.1 & 978.854 & 0.246 & 978.1 & 979.85 & -1.75 & 978.4 & 978.35 & 0.05 \\
\hline $\begin{array}{l}\text { ARIZONA- } \\
\text { SOCALIF }\end{array}$ & 3369.9 & 3368.54 & 1.36 & 3387.5 & 3395.1 & -7.6 & 3356.7 & 3355.1 & 1.6 \\
\hline ARIZONA-LADWP & 2663.3 & 2661.956 & 1.344 & 2685.6 & 2692.5 & -6.9 & 2648 & 2646.5 & 1.5 \\
\hline ARIZONA-PACE & -77 & -76.952 & -0.048 & -65.4 & -65 & -0.4 & -82.7 & -83 & 0.3 \\
\hline $\begin{array}{c}\text { ARIZONA-WAPA } \\
\text { R.M. }\end{array}$ & -64.6 & -64.4 & -0.2 & -64.6 & -64.4 & -0.2 & -64.6 & -64.4 & -0.2 \\
\hline $\begin{array}{l}\text { NEVADA- } \\
\text { SOCALIF }\end{array}$ & 67.9 & 67.762 & 0.138 & 70.7 & 70.75 & -0.05 & 65.8 & 66.25 & -0.45 \\
\hline NEVADA-PACE & 196.4 & 196.552 & -0.152 & 201.7 & 201.2 & 0.5 & 193.7 & 194.2 & -0.5 \\
\hline $\begin{array}{l}\text { MEXICO-CFE- } \\
\text { SANDIEGO }\end{array}$ & -154.9 & -155.048 & 0.148 & -149.6 & -150.4 & 0.8 & -157.2 & -157.4 & 0.2 \\
\hline $\begin{array}{l}\text { IMPERIALCA- } \\
\text { SANDIEGO }\end{array}$ & -87.1 & -87.118 & 0.018 & -87.4 & -87.45 & 0.05 & -87 & -86.95 & -0.05 \\
\hline $\begin{array}{l}\text { IMPERIALCA- } \\
\text { SOCALIF }\end{array}$ & 191.9 & 191.744 & 0.156 & 194.2 & 194.4 & -0.2 & 190.5 & 190.4 & 0.1 \\
\hline
\end{tabular}




\section{CHAPTER 6: High Level Transmission Tool Description}

This section gives a description of the TT tool on a block-diagram level.

\section{Connectivity Diagram with Real-Time Voltage Stability Analysis Tool and CAISO Visualization Software}

Figure 20 illustrates the connections and type of information to be exchanged PNNL's TT and RTVSA and visualization software. Details of the shown information exchange were provided in the previous section of this report.

Figure 20: Connections and Type of Information to be Exchanged PNNL's TT and RTVSA and Visualization Software

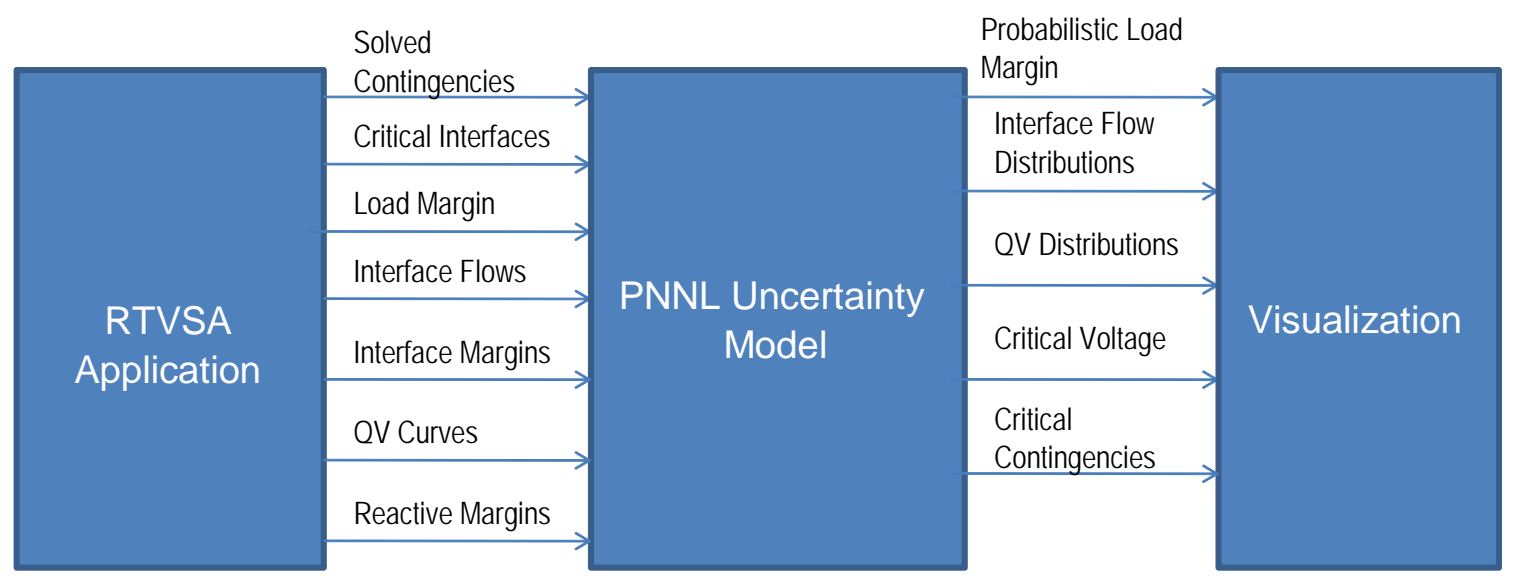

\section{Internal System Architecture}

The TT utilizes the output of existing RTVSA tool in California ISO to predict the available probabilistic voltage stability margin along the most important congested paths, worst case voltage drop, and reactive power margin for 1 to 3 hours ahead of time and in 5-minute resolution for a given set of contingencies. If congestion and voltage problems exist in the system, the tool suggests control actions in the form of advisory messages to mitigate the problem.

Figure 21 illustrates the internal architecture of the TT. 
Figure 21: Architecture of the Transmission Tool

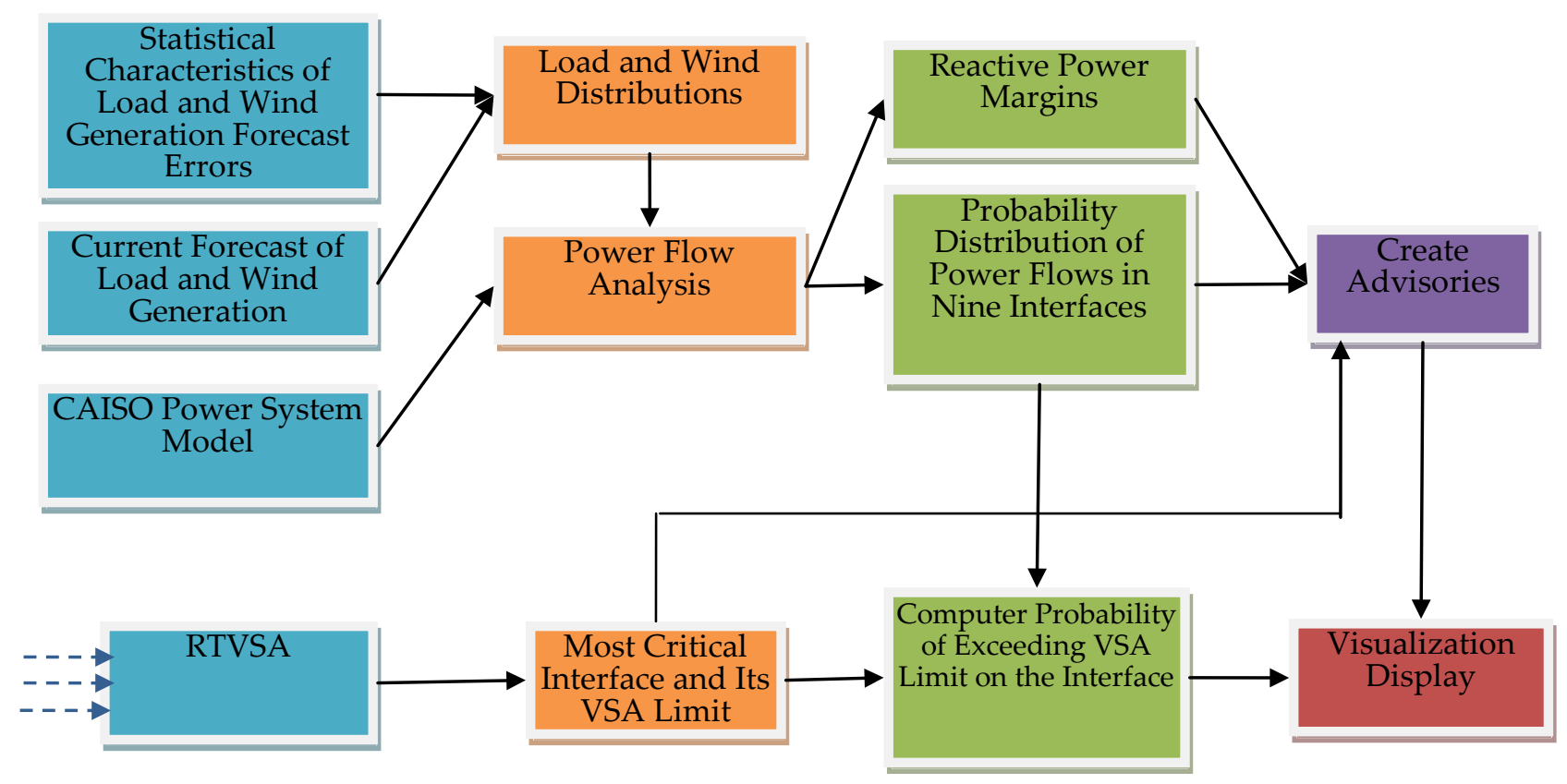

\section{Platform}

The transmission tool is a stand-alone application for a PC with Microsoft Windows operating system. The database used by the tool is Oracle Express. The transmission tool was developed in Visual Studio 2008, primarily Visual Basic, using Oracle Express. The tool will provide connectivity with the existing RTVSA tool and secondarily, for display purposes, with the visualization tool. An electronic help system is included with the application.

\section{System Features and Benefits for CAISO}

The analyzed impacts of TT include:

1. Impacts on congestion;

2. Impacts on voltage and transient stability margins, and

3. Impacts on voltage reductions and reactive power margins.

The impacts are analyzed in the base case and under all user-specified contingencies, so that the most limiting contingency is determined and addressed.

Information provided to the real-time dispatchers by transmission tool includes:

1. The probability of violation of transmission constraints; this probability can be compared against the corresponding threshold risk levels specified by the users. If the violation probability exceeds the threshold, the TT issues advisory information suggesting an increase of the security margin helping to lower the probability of violation to an acceptable level. 
2. The average and the maximum size of violations; the average size of violations are compared against their user-specified thresholds. If the average expected violation exceeds a userspecified threshold, the TT issues advisory information suggesting an increase of the security margin helping to lower the average size of violation to an acceptable level.

3. The available probability-based security margin (a distance to violation) and recommendations on its increase whenever is required, and

4. Visualization of the transmission impacts, real-time dispatcher alerts and advisory information on a WECC or California system map.

The proposed transmission tool has several very important advantages and opportunities for the California system operators:

- Better quantification of available security margins. Because the analyzed transmission impacts are caused by random variations of forecast errors in different parts of the system, they are not predictable in a deterministic sense. Based on a statistical analysis of multiple forecast errors, the tool provides a unique opportunity to adjust security margins depending on the risk (expected size and probability) of potential transmission violations.

- Better reliability level. By adjusting the system security margins on critical paths in the system, the tool helps to prevent potential violations caused by random variations of system load and variable generation around their forecasted values.

- Better utilization of transmission assets. In cases when the deterministic security margin is excessive, the tool will provide recommendations to reduce this margin based on the actual variability of the flows in the analyzed critical paths.

- Better situation awareness and predictive system monitoring. The TT algorithm is run for multiple look-ahead dispatch intervals and possible contingencies. Based on this information, system dispatchers will be informed about potential violations and associated risks on all critical paths in the system, and on the most critical contingencies as well as the expected time to violations.

- Preventive control. Because of its look-ahead feature, the TT algorithm leaves some time for mitigation measures, helping to reduce the expected size and probability of violations to an acceptable level.

\section{Module 1: Power Flow Module}

The power flow module contains a power flow solver based on the linearized incremental model. The power flow solver obtains power flow snapshots for all contingencies and future dispatch intervals from the RTVSA tool (e.g., generation, load and bus voltages etc.). The PTDF module produced PTDF factors used in the power flow solver. The uncertainty model is based on the state model described above. The Monte Carlo draws various system zonal loads and variable generation around their forecasted values based on the state uncertainty model.

Figure 22 shows the structure and connectivity of the power flow module. 


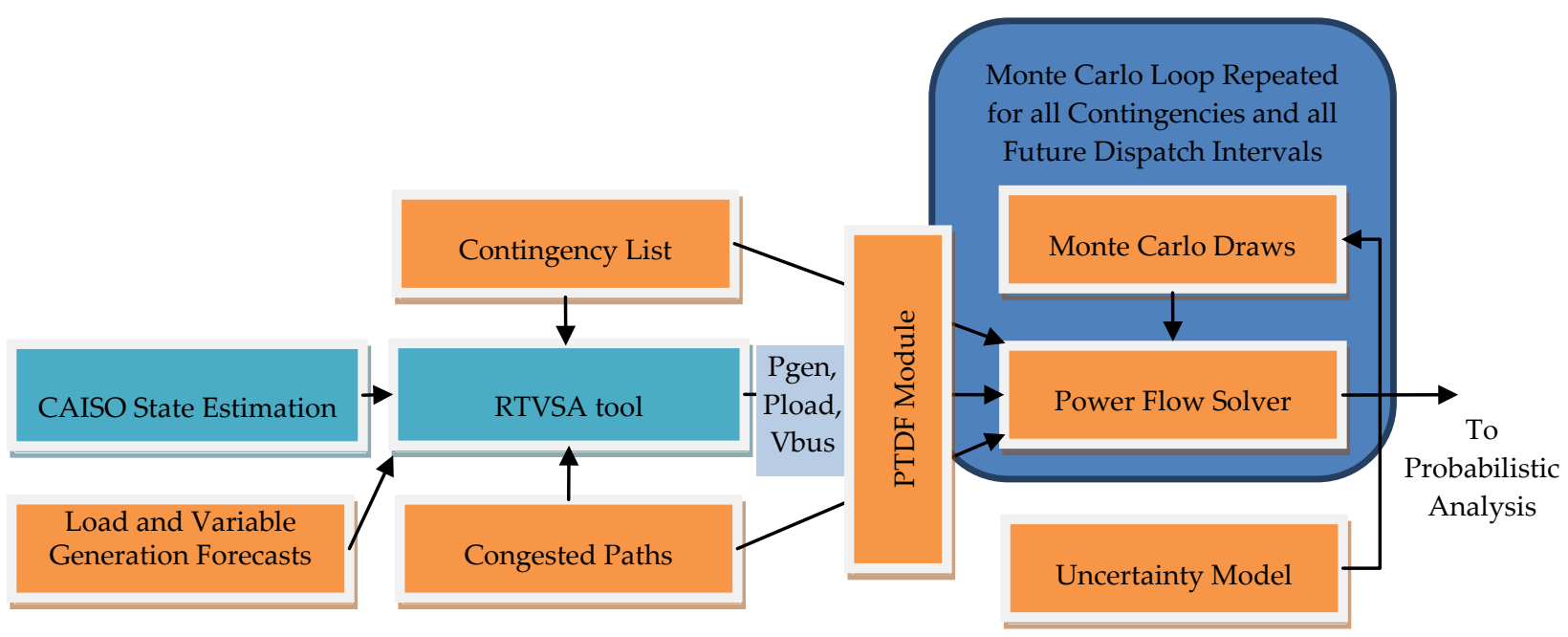

\section{Module 2: PTDF Module}

The purpose of the PTDF (power transfer distribution factor) module is to generate sensitivity of power flows in the analyzed congested paths to the changes in zonal loads and generation produced by Monte Carlo draws. This information is used by the power flow solver to evaluate changes of the power flows in congested paths caused by variations of zonal loads and generation from their forecasted values. In the industrial-grade version of the tool, the PTDF factors will be calculated internally. In the current prototype, these factors are calculated using Power World. The schematics of the PTDF module is shown in Figure 23.

Figure 23: PTDF Module

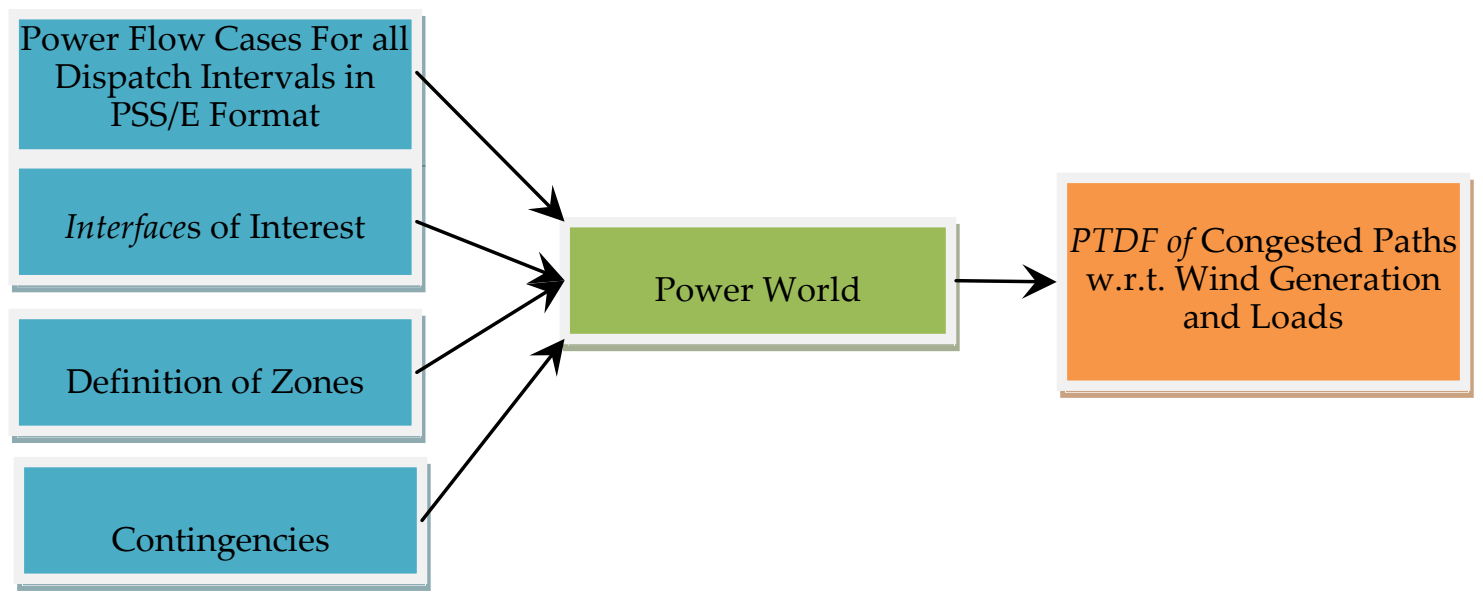


A snapshot of power flow cases for all analyzed contingencies and look-ahead dispatch intervals are received from the RTVSA application in PSLF format. The results of PTDF calculations are written into a database.

\section{Module 3: Uncertainty Module}

This module uses historical time series data on a number of variables (called state space variables) such as zonal loads, wind generation from various farms, etc. The actual information is compared with the forecasts, and the differences are used to build the state space model (WECC 2008a). The state space model preserves essential characteristics of the original data such as mathematical expectation, standard deviation, auto- and cross-correlation. The model produces numerous sets of generated samples that repeat statistical footprint of the original data (during the Monte Carlo draws).

Figure 24: Uncertainty Module

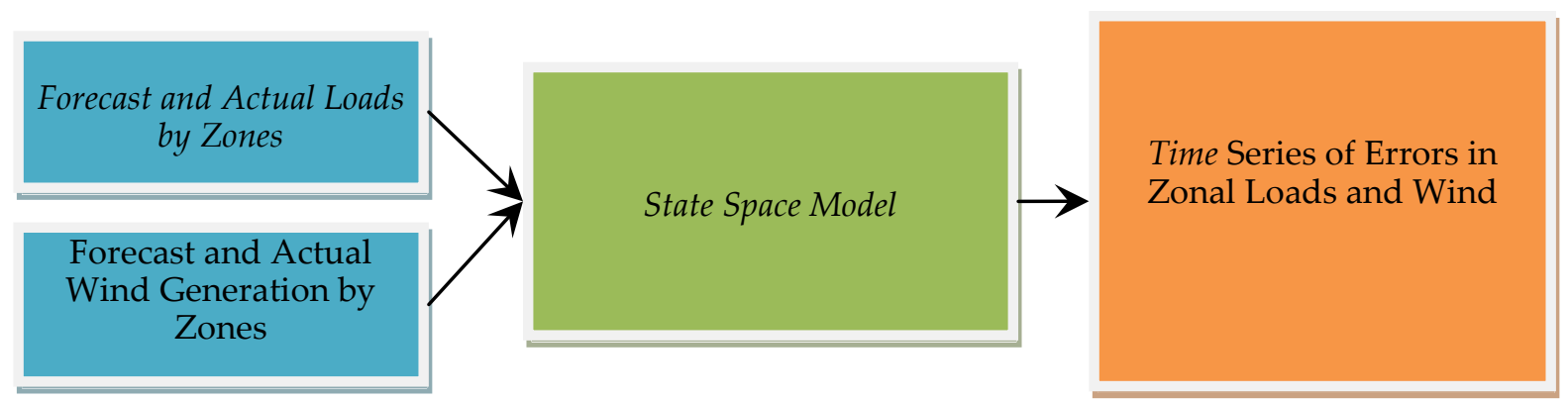

\section{Module 4: Probabilistic Analysis}

The output of power solver data collected for multiple Monte Carlo draws is fed into the probabilistic analysis module. The module builds histograms of power flows in selected critical paths, voltage levels at specified buses, and reactive power margin. The histograms are then converted into PDF and CDF of the corresponding variables. The distributions are compared against the corresponding transmission limits (posed by thermal, voltage, voltage and transient stability, and reactive power constraints). This comparison helps to evaluate the probability of system problems, and their average and maximum size, as described above. 


\section{CHAPTER 7: \\ User Interface Prototype}

\section{Graphic User Interface (GUI)}

This project was conducted with the idea of interfacing the transmission tool with the visualization tools. Nevertheless, for the purposes of demonstration of our prototype TT capabilities and possible ways of presenting its results, PNNL created its own visualization output and graphical user interface (GUI). Figure 25 shows a snapshot of the main GUI of the prototype transmission tool. Figure 25 also displays active power flows in 10 critical interfaces (right upper corner of the GUI panel). The tool provides 1-hour ahead, 2-hour ahead, and 3hour ahead analyses. Actual locations of substations and transmisison lines are plotted on the Google Earth platfom incorporated in the transmisison tool. Unacceptable probabilities of power flows exceeding their transmission limits are identified as red bars in Figure 25.

Figure 25: Main GUI of the Transmission Tool

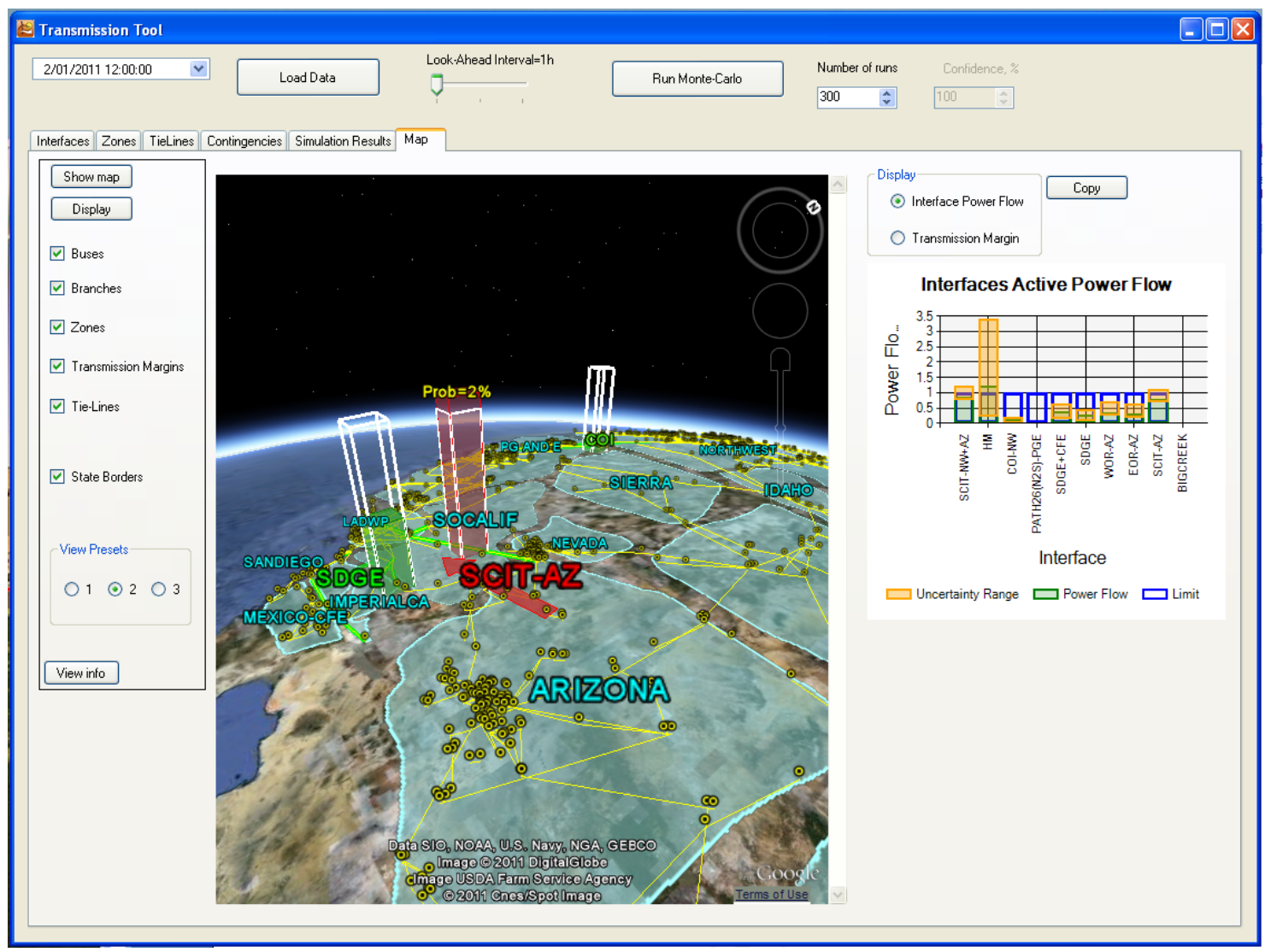




\section{Presenting Simulation Results}

Figure 26 shows the interfaces' active power flows along the uncertainty range, and the limits are also shown in Figure 26.

Figure 26: Interfaces Active Power Flow

Interfaces Active Power Flow

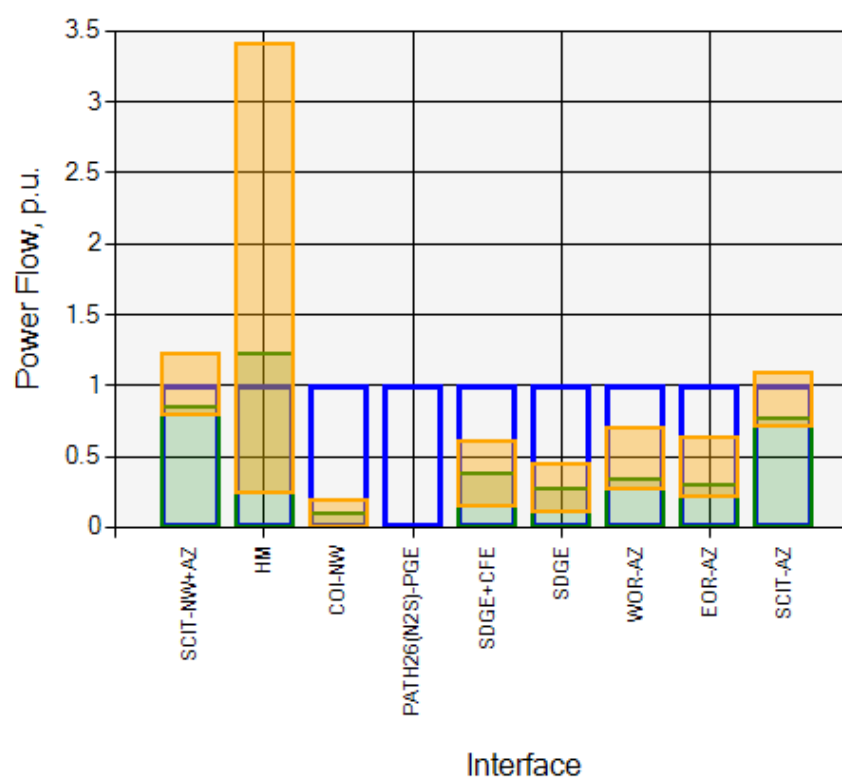

Figure 27 shows the transmission load margin in terms of interface active power flows along 10 interfaces.

Figure 27: Transmission Load Margin

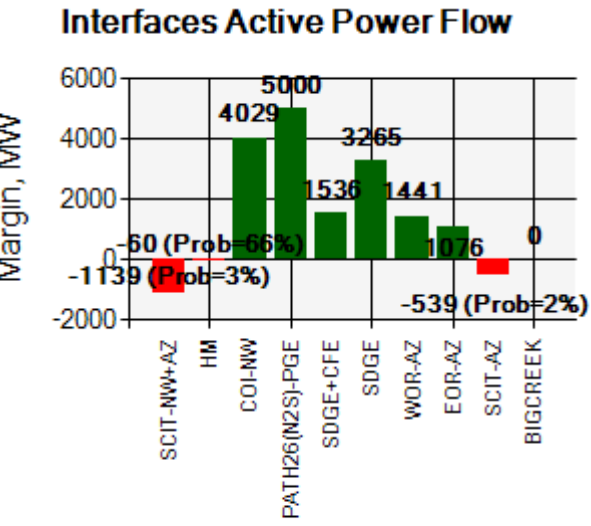

Interface 
Figure 28 shows results of the incremental power flow simulations in a table format. The probability distributions of the power flow for different interfaces are also provided in the tool. The user can pick up any interface of interest to see the distribution.

Figure 28: Simulation Results - Incremental Power Flow

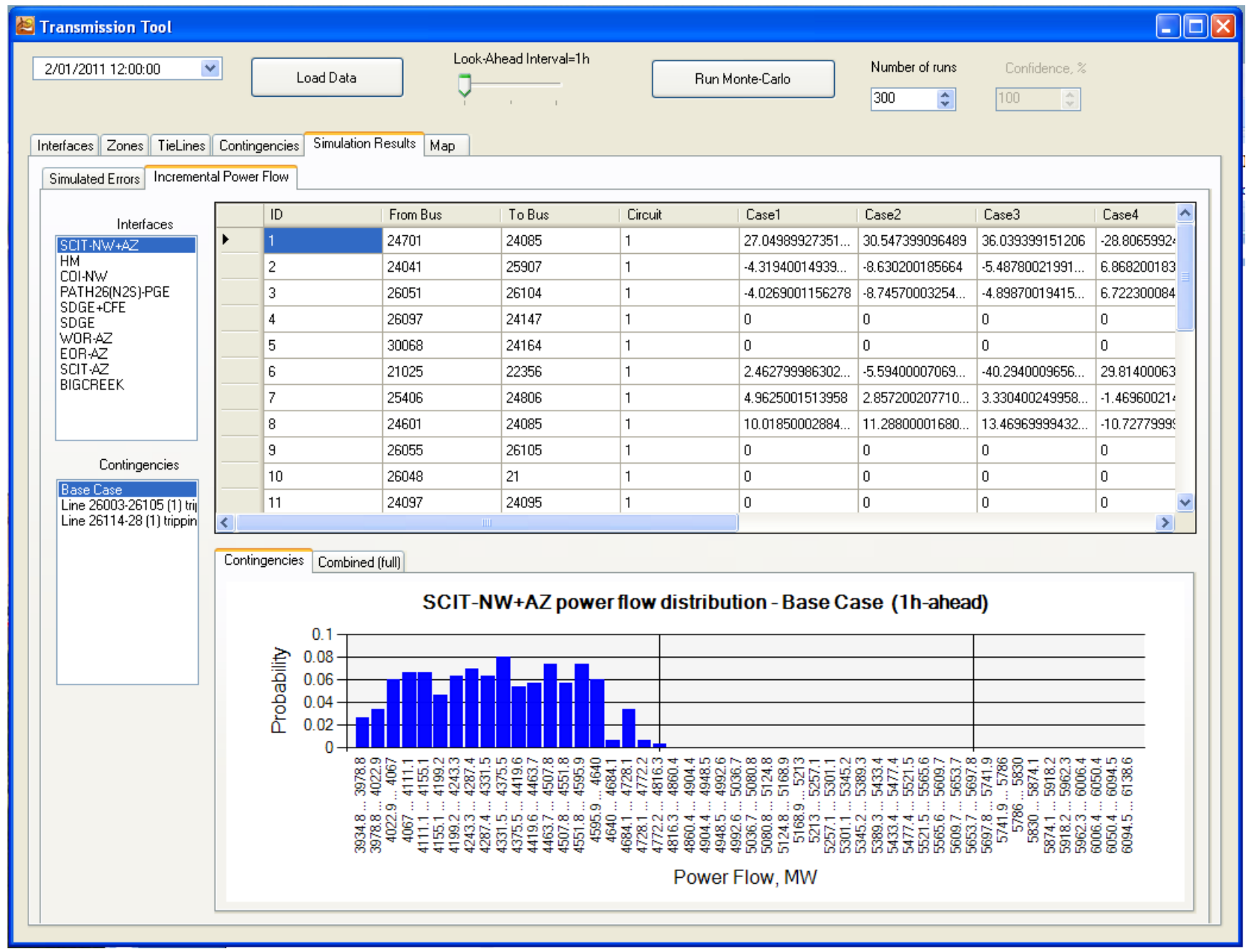

Figure 29 shows the interface data for the base case and two contingency cases. The data items include interface thermal limits (MW), total active power (MW), total reactive power (MVAr) and power flow margin (MW). Figure 30 shows the information regarding zones. The generation (MW), load (MW) and wind generation (MW) are shown in the table. 
Figure 29: Interfaces' Information

\begin{tabular}{|c|c|c|c|c|c|c|c|c|}
\hline \multicolumn{7}{|l|}{ Transmission Tool } & \multicolumn{2}{|c|}{$-\square x$} \\
\hline 2/01/2011 12:00:00 & \multicolumn{2}{|c|}{ Load Data } & \multicolumn{2}{|c|}{ Look-Ahead Interval=1h } & \multicolumn{2}{|c|}{ Run Monte-Carlo } & Number of runs & \multirow{2}{*}{$\begin{array}{l}\text { Confide } \\
100\end{array}$} \\
\hline 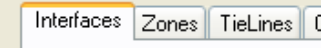 & Contingencies & Simulation Results & Its Map & & & & & \\
\hline \multirow{11}{*}{\begin{tabular}{|l|} 
Base Case \\
Lime 26003-26105 (1) trippin \\
Line 26114-28 (1) tripping
\end{tabular}} & ID & & Name & $\begin{array}{l}\text { Thermal Limit } \\
\text { (MW) }\end{array}$ & Ptotal (MW) & Qtotal (MVar) & \multicolumn{2}{|l|}{ Margin $(\mathrm{MW})$} \\
\hline & 1 & & SCIT $-N W+A Z$ & 5000 & 4308.7 & -67.6 & \multicolumn{2}{|l|}{$691.2999999999 \ldots$} \\
\hline & 2 & & $\mathrm{HM}$ & 25 & 30.8 & 16.1 & \multicolumn{2}{|l|}{-5.8} \\
\hline & 3 & & $\mathrm{COINNW}$ & 5000 & 557.4 & 96 & \multicolumn{2}{|l|}{4442.6} \\
\hline & 4 & & PATH26(N2S).P... & 5000 & 0 & 0 & \multicolumn{2}{|l|}{5000} \\
\hline & 5 & & $\mathrm{SDGE}+\mathrm{CFE}$ & 4000 & 1560.9 & -136.1 & \multicolumn{2}{|l|}{2439.1} \\
\hline & 6 & & SDGE & 6000 & 1645.9 & -131.3 & \multicolumn{2}{|l|}{4354.1} \\
\hline & 7 & & WOR $\cdot A Z$ & 5000 & 1754.4 & .329 .8 & \multicolumn{2}{|l|}{3245.6} \\
\hline & 8 & & $E O R \cdot A Z$ & 3000 & 924.2 & -59.3 & \multicolumn{2}{|l|}{2075.8} \\
\hline & 9 & & SCIT $A Z$ & 5600 & 4308.7 & -67.6 & \multicolumn{2}{|l|}{1291.3} \\
\hline & 10 & & BIGCREEK & 0 & 0 & 0 & \multicolumn{2}{|l|}{0} \\
\hline
\end{tabular}

Figure 30: Zonal Information

\begin{tabular}{|c|c|c|c|c|c|c|c|c|c|c|c|}
\hline \multicolumn{8}{|c|}{ Transmission Tool } & & & \multicolumn{2}{|c|}{$-\square x$} \\
\hline \multicolumn{3}{|c|}{ 2/01/2011 12:00:00 } & \multicolumn{2}{|c|}{ Load Data } & \multicolumn{2}{|c|}{ Look-Ahead Interval=1h } & Run Monte-Carlo & \multicolumn{2}{|c|}{ Number of runs } & \multicolumn{2}{|c|}{ Confide } \\
\hline \multirow[t]{2}{*}{ Interfaces } & Zones & TieLines & Contingencies & Simulation Results & Map & & & & & & \\
\hline & ID & & WECCID & Name & $\begin{array}{l}\text { Generation } \\
\text { (MW) }\end{array}$ & Load (MW) & Wind (MW) & & & \multirow{13}{*}{\multicolumn{2}{|c|}{$\hat{=}$}} \\
\hline \multirow[t]{12}{*}{1} & 1 & & 80 & SMUD-80 & 1690.63 & 1824.83 & 0 & & & & \\
\hline & 2 & & 30 & $P G A E-30$ & 11917.5 & 11939.11 & 0 & & & & \\
\hline & 3 & & 50 & BCHYD-50 & 4859.11 & 6373.17 & 0 & & & & \\
\hline & 4 & & 40 & NWEST-40 & 21380.42 & 18142.86 & 0 & & & & \\
\hline & 5 & & 24 & SCE-24 & 7404.7 & 11729.94 & 0 & & & & \\
\hline & 6 & & 60 & IDAHO-60 & 2068.08 & 1420.89 & 0 & & & & \\
\hline & 7 & & 26 & LADWP-26 & 2570.89 & 3178.25 & 0 & & & & \\
\hline & 8 & & 70 & PSC-70 & 3988.35 & 5181.03 & 0 & & & & \\
\hline & 9 & & 10 & NMEX-10 & 2500.35 & 2453.25 & 0 & & & & \\
\hline & 10 & & 14 & $A R I Z: 14$ & 12032.22 & 7544.25 & 0 & & & & \\
\hline & 11 & & 64 & SPP-64 & 869.49 & 1138.75 & 0 & & & & \\
\hline & 12 & & 54 & ALBER-54 & 7486.58 & 7552.82 & 0 & & & & \\
\hline
\end{tabular}

Figure 31 through Figure 33 show power flow distributions of the base case, contingency case 1, and contingency case 2 (1-hour ahead) for the interface of San Diego Gas \& Electric (SDG\&E). 
Figure 31: Probability of Power Flow for Base Case

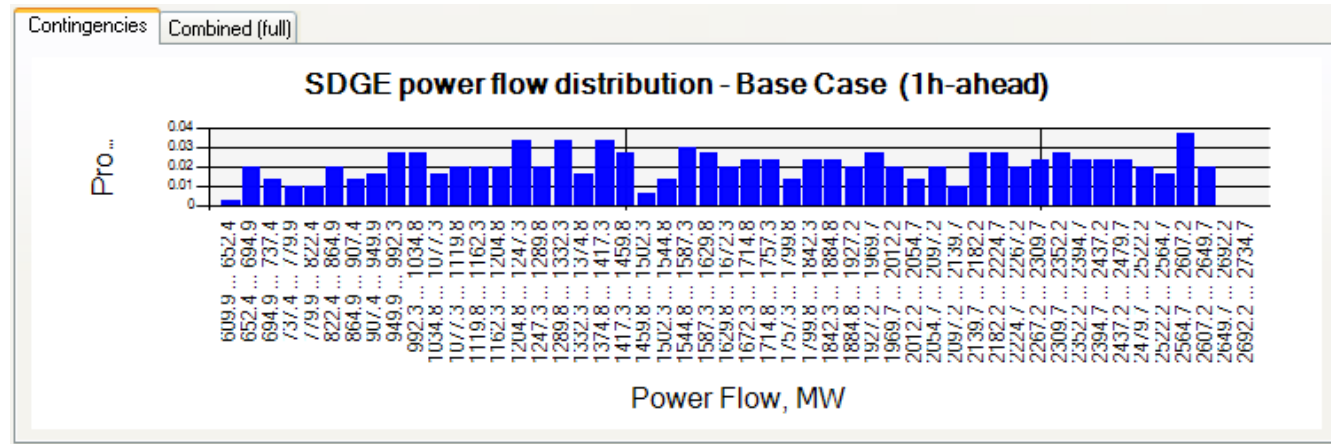

Figure 32. Probability of Power Flow for Contingency Case - 1

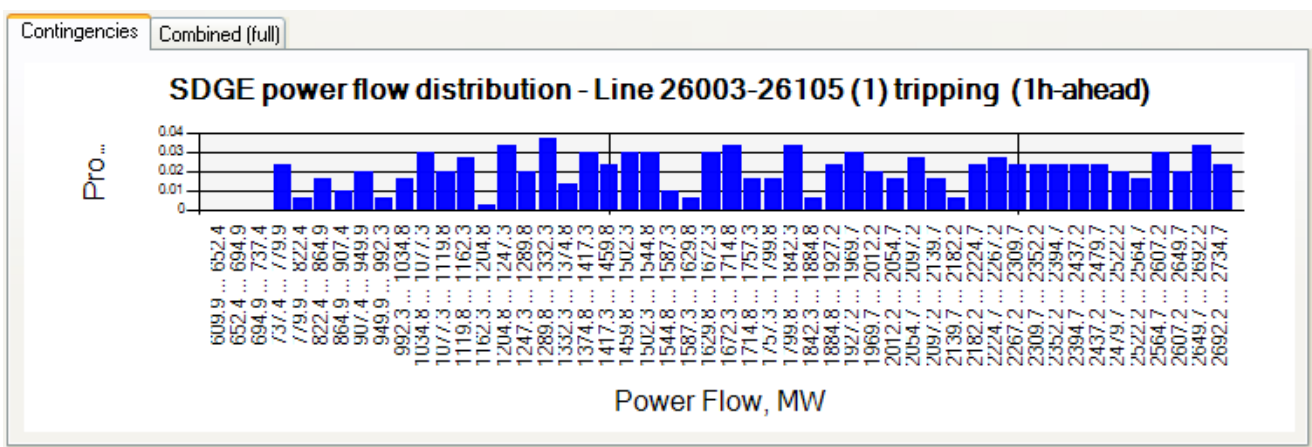

Figure 33. Probability of Power Flow for Contingency Case - 2

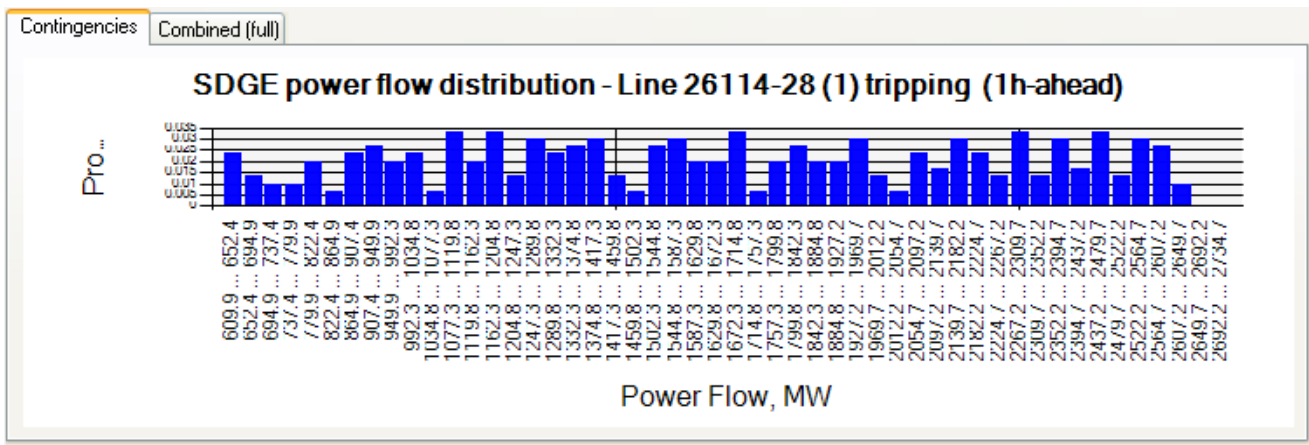


Figure 34 shows the probability of an interface power flow exceeding the limit.

Figure 34: Probability Distribution of a Power Flow
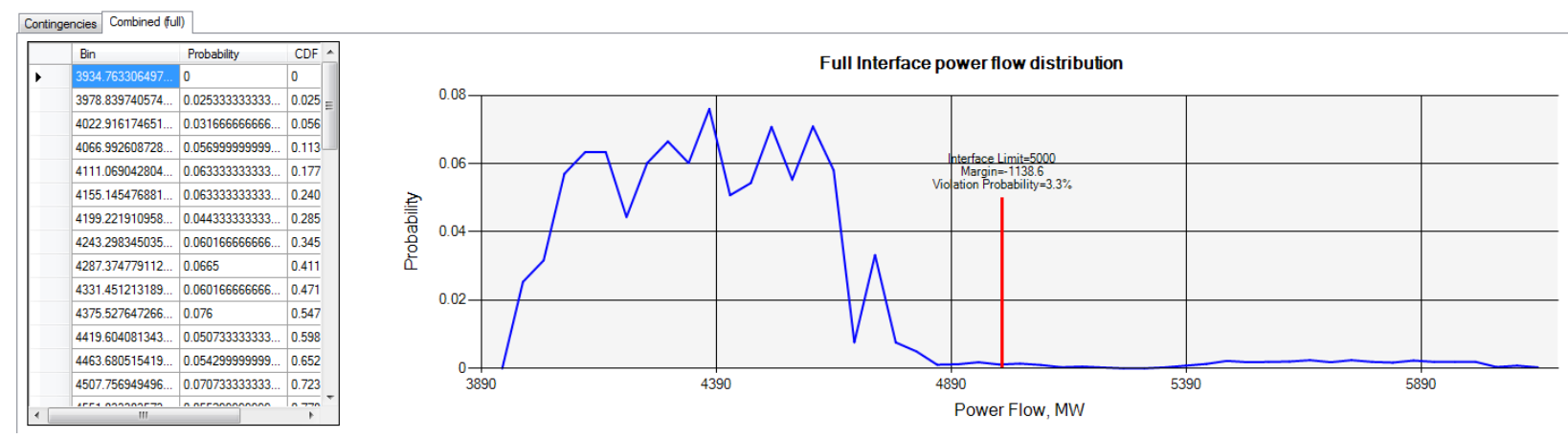

\section{Database Structure}

The data used in the transmission tool include: interfaces, zones, and tie lines information. Two contingency cases are used for demonstration purposes. Table 6 through Table 10 show examples of the data used in the transmission tool. The data provided in the tables are for demonstration purpose only and do not correspond to a real case.

Table 6: Contingency Cases

\begin{tabular}{ccc}
\hline ID & Description & Probability \\
\hline 1 & Line 26003-26105 (1) tripping & $3 \%$ \\
2 & Line 26114-28 (1) tripping & $2 \%$ \\
\hline
\end{tabular}

Table 7: Transmission Limits and Margin for Base Case

\begin{tabular}{cccccc}
\hline ID & Name & $\begin{array}{c}\text { Thermal Limit } \\
(\mathrm{MW})\end{array}$ & P Total (MW) & Q Total (MVAr) & $\begin{array}{c}\text { Margin } \\
(\mathrm{MW})\end{array}$ \\
\hline 1 & SCIT-NW+AZ & 5000 & 4308.7 & -67.6 & 691.3 \\
2 & HM & 25 & 30.8 & 16.1 & -5.8 \\
3 & COI-NW & 5000 & 557.4 & 96 & 4442.6 \\
4 & PATH26(N2S)-PGE & 5000 & 0 & 0 & 5000 \\
5 & SDGE+CFE & 4000 & 1560.9 & -136.1 & 2439.1 \\
6 & SDGE & 6000 & 1645.9 & -131.3 & 4354.1 \\
7 & WOR-AZ & 5000 & 1754.4 & -329.8 & 3245.6 \\
8 & EOR-AZ & 3000 & 924.2 & -59.3 & 2075.8 \\
9 & SCIT-AZ & 5600 & 4308.7 & -67.6 & 1291.3 \\
\hline
\end{tabular}


Table 8: Transmission Limits and Margin for a Contingency Case

\begin{tabular}{cccccc}
\hline ID & Name & $\begin{array}{c}\text { Thermal Limit } \\
(\mathrm{MW})\end{array}$ & P Total (MW) & Q Total (MVAr) & $\begin{array}{c}\text { Margin } \\
(\mathrm{MW})\end{array}$ \\
\hline 1 & SCIT-NW+AZ & 5000 & 5685.1 & 1139.5 & -685.1 \\
2 & HM & 25 & 60.1 & -3.1 & -35.1 \\
3 & COI-NW & 5000 & 125.5 & 379.3 & 4874.5 \\
4 & PATH26(N2S)-PGE & 5000 & 0 & 0 & 5000 \\
5 & SDGE+CFE & 4000 & 1560.6 & -133.7 & 2439.4 \\
6 & SDGE & 6000 & 1739.1 & -144.6 & 4260.9 \\
7 & WOR-AZ & 5000 & 3111.7 & -407.3 & 1888.3 \\
8 & EOR-AZ & 3000 & 1634.3 & 154.1 & 1365.7 \\
9 & SCIT-AZ & 5600 & 5685.1 & 1139.5 & -85.1 \\
\hline
\end{tabular}

Table 9: Zonal Information

\begin{tabular}{|c|c|c|c|c|c|}
\hline ID & WECC ID & Name & $\begin{array}{c}\text { Generation } \\
(\mathrm{MW})\end{array}$ & Load (MW) & Wind (MW) \\
\hline 1 & 80 & SMUD-80 & 1690.63 & 1824.83 & 0 \\
\hline 2 & 30 & PGAE-30 & 11917.5 & 11939.11 & 0 \\
\hline 3 & 50 & BCHYD-50 & 4859.11 & 6373.17 & 0 \\
\hline 4 & 40 & NWEST-40 & 21380.42 & 18142.86 & 0 \\
\hline 5 & 24 & SCE-24 & 7404.7 & 11729.94 & 0 \\
\hline 6 & 60 & IDAHO-60 & 2068.08 & 1420.89 & 0 \\
\hline 7 & 26 & LADWP-26 & 2570.89 & 3178.25 & 0 \\
\hline 8 & 70 & PSC-70 & 3988.35 & 5181.03 & 0 \\
\hline 9 & 10 & NMEX-10 & 2500.35 & 2453.25 & 0 \\
\hline 10 & 14 & ARIZ-14 & 12032.22 & 7544.25 & 0 \\
\hline 11 & 64 & SPP-64 & 869.49 & 1138.75 & 0 \\
\hline 12 & 54 & ALBER-54 & 7486.58 & 7552.82 & 0 \\
\hline 13 & 62 & MONT-62 & 1004.07 & -623.07 & 0 \\
\hline 14 & 90 & TID-90 & 349.79 & 283.21 & 0 \\
\hline 15 & 22 & SDGE-22 & 916.7 & 2532.92 & 0 \\
\hline 16 & 18 & NEVAD-18 & 2647.7 & 2059.28 & 0 \\
\hline 17 & 73 & WAPRM-73 & 3475.82 & 2692.75 & 0 \\
\hline 18 & 65 & PACE-65 & 4424.74 & 4153.22 & 0 \\
\hline 19 & 20 & CFE-20 & 1158.68 & 1072.36 & 0 \\
\hline 20 & 52 & FORTS-52 & 265.54 & 595.44 & 0 \\
\hline 21 & 21 & IMPER-21 & 724.79 & 631.67 & 0 \\
\hline 22 & 19 & WAPLC-19 & 1723.97 & 799.84 & 0 \\
\hline 23 & 41 & CRAGV-41 & 0 & 0 & 0 \\
\hline 24 & 63 & WAPUM-63 & -0.29 & 64.96 & 0 \\
\hline 25 & 39 & TRNBY-39 & 0 & 0 & 0 \\
\hline
\end{tabular}


Table 10: Tie Line Information

\begin{tabular}{cccccc}
\hline ID & From Bus & To Bus & Circuit & P (MW) & Q (MVAr) \\
\hline 1 & 24701 & 24085 & 1 & 197.8 & 11.7 \\
2 & 24041 & 25907 & 1 & 69.9 & -29.2 \\
3 & 26051 & 26104 & 1 & 105.1 & -30.5 \\
4 & 26097 & 24147 & 1 & 238.4 & 4.3 \\
5 & 30068 & 24164 & 1 & 0 & 0 \\
6 & 21025 & 22356 & 1 & -19 & 52.8 \\
7 & 25406 & 24806 & 1 & -57.4 & -2.9 \\
8 & 24601 & 24085 & 1 & -37.4 & -18.3 \\
9 & 26055 & 26105 & 1 & 0 & 0 \\
10 & 26048 & 21 & 1 & 0 & 0 \\
11 & 24097 & 24095 & 1 & 0 & 0 \\
12 & 89 & 88 & 1 & 0 & 0 \\
13 & 26003 & 26105 & 2 & 450.1 & -30.1 \\
14 & 26099 & 26094 & 1 & 235 & 96.5 \\
15 & 24041 & 25908 & 1 & 69.9 & -29.2 \\
16 & 26003 & 26079 & 1 & 828.9 & 5 \\
17 & 24701 & 24085 & 1 & 197.8 & 11.7 \\
18 & 24601 & 24085 & 1 & -37.4 & -18.3 \\
19 & 30061 & 24163 & 1 & 0 & 0 \\
20 & 26003 & 26115 & 1 & 723 & -25.7 \\
21 & 21007 & 24804 & 1 & 36.5 & 19.4 \\
22 & 80 & 24165 & 1 & 0 & 0 \\
23 & 21076 & 24806 & 1 & 58.5 & -7.7 \\
24 & 22536 & 22360 & 1 & 798.9 & -47 \\
25 & 26003 & 26105 & 1 & 450.1 & -30.1 \\
26 & 15021 & 99012 & 1 & 0 & 0 \\
\hline & & 1 & & \\
\hline
\end{tabular}




\section{CHAPTER 8: Conclusions}

In this report, the development of a prototype transmission tool is presented. The design consideration, system architecture, simulation results and graphic user interface are described. The system architecture and system features are described. The power system model and the methodology to determine probabilistic thermal congestion limits based on power transfer distribution factor are presented. The five key system modules (e.g., power flow module, PTDF module, uncertainty module, probability congestion module and interface module) are also discussed in the report. This tool can be a very innovative and useful operating tool for reliable operations of power systems for grid operators. Future work could be to install and test the tool in a real control center using an actual system model and data. 


\section{CHAPTER 9: References}

Bigwood Systems, Inc. 2012. “BSI's Real-Time Voltage Stability.” Bigwood Systems, Inc. [Online.] Available: http://www.bigwoodsystems.com/products.asp?ItemID=118\&rcid=69\&pcid=0\&cid=69.

Chiang, H.-D., L. Jin, M. Varghese, S. Ghosh, and H. Li. 2009. “Linear and Nonlinear Methods for Contingency Analysis in On-Line Voltage Security Assessments." In Proc. IEEE General Meeting, July 26-30, 2009.

Department of Market Monitoring - California ISO. 2007. “Inter-Zonal Congestion Management Market." April 2007. [Online.] Available: http://www.caiso.com/1bb7/1bb77ace17280.pdf.

Li, H., H.-D. Chiang, and J. Tong. 2004. “An On-Line Tool for Voltage Stability Assessment and Control of Large-Scale Power Systems." Bulk Power System Dynamics and Control - VI, Aug. 22-27, 2004, Cortina d'Ampezzo, Italy. [Online.] Available: areeweb.polito.it/eventi/irep2004/Session\%20B1/B1_4.pdf.

Makarov, Y. V., J. F. Reyes-Spindola, N. Samaan, R. Diao, and R. P. Hafen. 2010. “Wind and Load Forecast Error Model for Multiple Geographically Distributed Forecasts." Proc. 9th International Workshop on Large-Scale Integration of Wind Power into Power Systems as well as on Transmission Networks for Offshore Wind Power Plants, Québec City, Québec, Canada, October 18-19, 2010.

Salem-Natarajan, D., L. Zhao, W. Shao; M. Varghese, S. Ghosh, M. Subramanian, G. Lin, H.-D. Chiang, and H. Li. 2008. "State Estimator for CAISO Market and Security Applications - Relevance and Readiness." IEEE PES General Meeting, Pittsburgh, Pennsylvania, USA, July 20-24, 2008. [Online.] Available: www.ece.neu.edu/ abur/CAMS/CA-ISO.ppt.

Varghese, M., D. Salem-Natarajan, S. Ghosh, H. D. Chiang, and H. Li. 2008. “Design and Implementation of Real-Time Voltage Stability Analysis at CAISO." Proc. of IEEE General meeting, July 2008.

WECC - Western Electricity Coordinating Council, Technical Studies Subcommittee. 2008a. WECC 2008 Path Rating Catalog. January 2008. Western Electricity Coordinating Council, Salt Lake City, Utah.

WECC - Western Electricity Coordinating Council, Operating Transfer Capability Policy Committee. 2008b. Approved 2008 - 2009 Winter Operating Transfer Capability (OTC) Limits. Western Electricity Coordinating Council, Salt Lake City, Utah. October 31, 2008. Available at http://www.wecc.biz/documents/library/OTC/20082009\%20Winter\%20Operating\%20Transfer\%20Capability\%20(OTC)\%20Limits\%20(2)\%2 0(3).pdf 
WECC - Western Electricity Coordinating Council. July 2007. “WECC Data Preparation Procedural Manual for Power Flow and Stability Studies," Rev. 5.0. Western Electricity Coordinating Council, Salt Lake City, Utah. Accessed December 2009 at http://www.wecc.biz/documents/library/SRWG/dppm5.0.pdf.

WECC - Western Electricity Coordinating Council. October 25, 2005. “WECC Reliability Coordination Center Requirements: Request for Information and Pricing (RFIP)." Western Electricity Coordinating Council, Salt Lake City, Utah. Accessed November 2009 at http://www.wecc.biz/documents/2005/News/WECC_RCC_RFIP_10-25-05.pdf (undated webpage). 


\section{CHAPTER 10: Glossary}

$\begin{array}{ll}\text { CAISO } & \text { California Independent System Operator } \\ \text { CDF } & \text { cumulative distribution function } \\ \text { CEC } & \text { California Energy Commission } \\ \text { CIEE } & \text { California Institute for Energy and Environment } \\ \text { CPF } & \text { continuation power flow } \\ \text { EMS } & \text { energy management system } \\ \text { ISO } & \text { Independent System Operator } \\ \text { MW } & \text { megawatt } \\ \text { OTC } & \text { operating transfer capability } \\ \text { PDF } & \text { probability density function } \\ \text { PIER } & \text { Public Interest Energy Research } \\ \text { PNNL } & \text { Pacific Northwest National Laboratory } \\ \text { PTDF } & \text { power transfer distribution factor } \\ \text { RD\&D } & \text { research, development, and demonstration } \\ \text { RTVSA } & \text { real-time voltage stability analysis } \\ \text { TC } & \text { transmission constraint } \\ \text { TT } & \text { transmission tool } \\ \text { VSA } & \text { voltage stability analysis } \\ \text { VSA\&E } & \text { voltage stability analysis and enhancement } \\ \text { WECC } & \text { Western Electricity Coordinating Council } \\ & \end{array}$




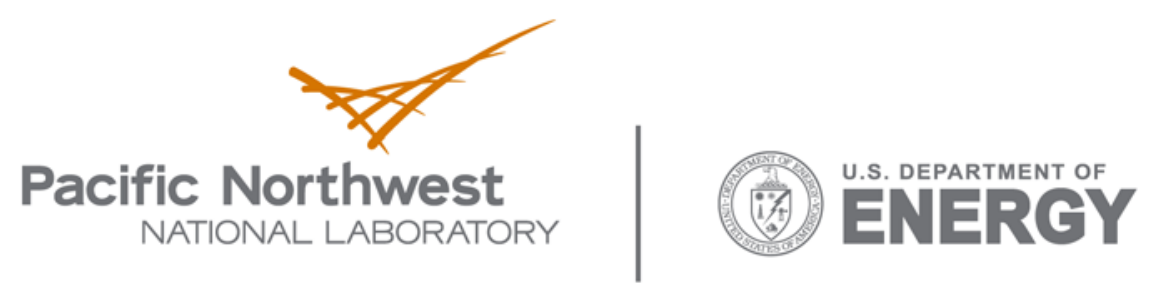

902 Battelle Boulevard

P.O. Box 999

Richland, WA 99352

1-888-375-PNNL (7665)

www.pnl.gov 